桌

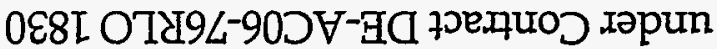

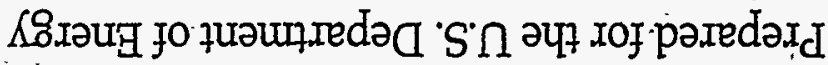

$\forall \exists \perp S \forall W$

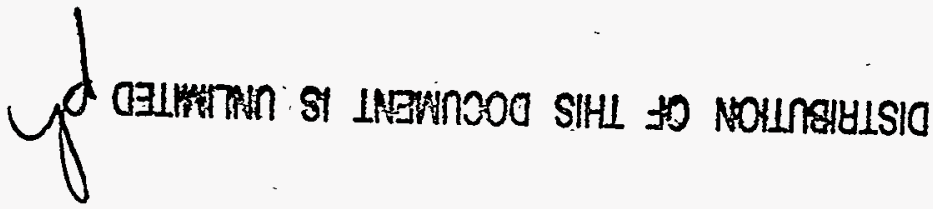

866I KEW

ełn '

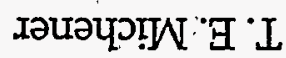

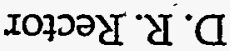

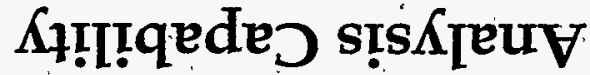

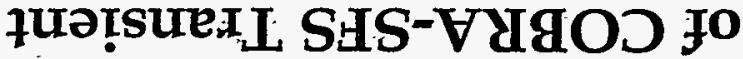

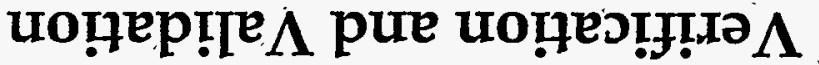

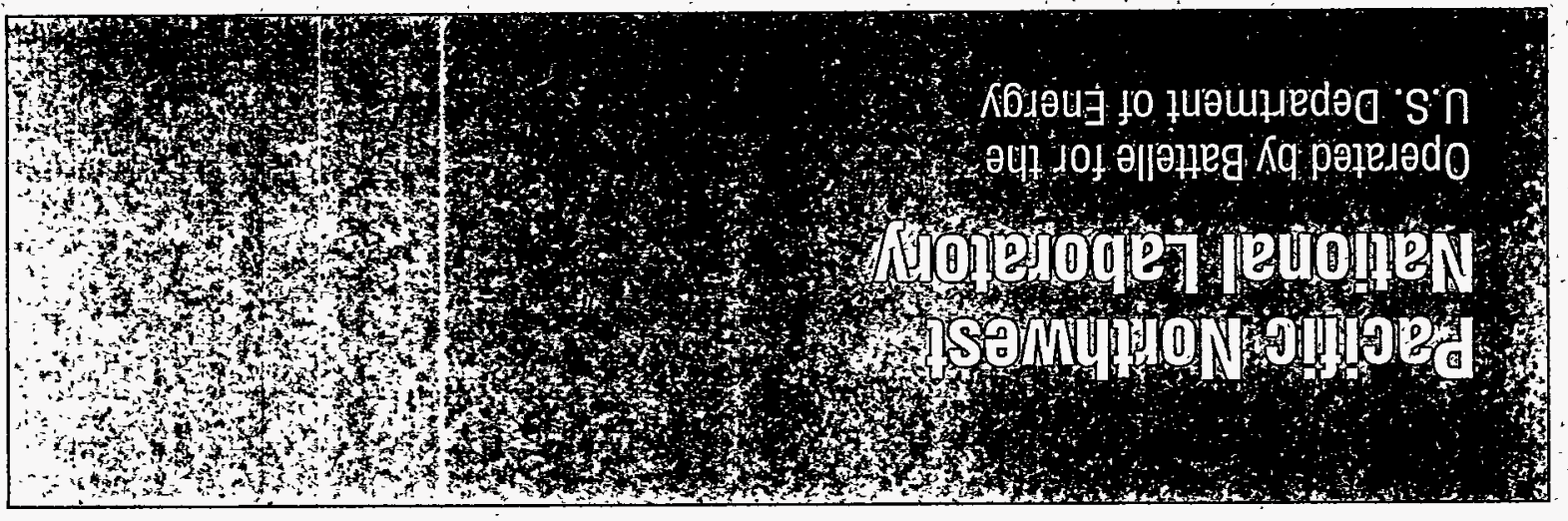




\section{DISCLAIMER}

This report was prepared as an account of work sponsored by an agency of the United States Government. Neither the United States.Government nor any agency thereof, nor Battelle Memorial Institute, nor any of their employees, makes any warranty, express or implied, or assumes any legal liability or responsibility for the accuracy, completeness, or usefulness of any information, apparatus, product, or process disclosed, or represents that its use would not infringe privately owned rights. Reference hèrein to any specific commercial product, process, or service by trade name, trademark, manufacturer, or otherwise does not necessarily constitute or imply its endorsement, recommendation, or favoring by the United States Govemment or any agency thereof, or Battelle Memorial Institute. The views and opinions of authors expressed herein do not necessarily state or reflect those of the United States Government or any agency thereof.'

\section{PACIFIC NORTHWEST NATIONAL LABORATORY operated by BATTELLE for the UNITED STATES DEPARTMENT OF ENERGY under Contract DE-AC06-76RLO 1830}

Printed in the United States of America

Available to DOE and DOE contractors from the

Office of Scientific and Technical Information, P.O. Box 62, Oak Ridge, TN 37831; prices available from (615) 576-8401.

Available to the public from the National Technical Information Service, U.S. Department of Commerce, 5285 Port Royal Rd., Springfield, VA 22161 


\section{DISCLAIMER}

Portions of this document may be illegible in electronic image products. Images are produced from the best available original document. 


\title{
Verification and Validation of COBRA-SFS Transient Analysis Capability
}

\author{
D. R. Rector \\ T. E. Michener \\ J. M. Cuta
}

May 1998

Prepared for

the U.S. Department of Energy

under Contract DE-AC06-76RLO 1830

Pacific Northwest National Laboratory

Richland, Washington 99352 



\section{Summary}

The work described in this document provides verification and validation of the transient capability in the COBRA-SFS code by presenting a set of comparisons between code calculations and analytical solutions for selected transient heat transfer and fluid flow problems, and between code calculations and transient experimental data obtained in spent fuel storage cask tests. Comparison to analytical solutions show that the conservation equations and mathematical models for heat transfer are correctly coded into the software. The cases selected for these validation calculations include conduction in a plate with a step change in boundary temperature, conduction in a plate with uniform internal heat generation, and conduction in a cylinder with a step change in boundary temperature. In these validation cases, the temperatures calculated with the code are essentially identical to the analytical solution for the problem.

Cases of analytical solutions for transient conditions where the flow channel undergoes a step change in the pressure gradient were selected for verification of the implementation of the momentum equation in COBRA-SFS. The exact solution describes the evolution of the velocity profile over time in response to the new pressure gradient. The velocity profiles calculated with the code using a zero-slip at the wall boundary condition are in excellent agreement with the transient analytical solution and for the initial steady-state profile. For the case of transient flow in a pipe, a lumped channel model using the empirical friction factor correlation for laminar flow provides a reasonable approximation of the transient behavior, and is in exceilent agreement with the final steady-state conditions.

Validation of the transient capability in the code is obtained by comparing calculational results with experimental data obtained in the TN24P cask and the PSN/VSC-17 cask. For the TN24P cask test program, the selected transient consists of changing the backfill gas from helium to air. Only one change was made to the input model originally developed for the steady-state analysis of the TN24P test program. The emissivity of the basket supporting the fuel assemblies was changed from 0.8 to 0.6 . This results in a slightly conservative estimate of the initial conditions, with the calculated temperatures approximately $4^{\circ} \mathrm{C}$ above the measured values in the hot assembly. The temperatures calculated in COBRA-SFS are well within the measurement uncertainty all during the transient, and follow very precisely the shape of the transient temperature curves.

For the PSN/VSC-17 cask test program, the final transient of the test series was selected for comparison to COBRA-SFS calculations. In this transient, the backfill gas in the Multi-assembly Sealed Basket (MSB) is helium and the vents on the air annulus between the MSB and the concrete outer shell of the cask are changed from all vents closed to all vents open. The COBRA-SFS calculations were performed with no changes to the input model developed for steady-state analysis of the PSN/VSC-17 data. The transient results obtained with the code are in excellent agreement with the measured temperatures all through this transient, but the final steady state is slightly more conservative than the test data. The difference is less than $7^{\circ} \mathrm{C}$, however, and given the overall measurement uncertainty and the unavoidable modeling uncertainties, these results constitute a very reasonable representation of the transient heat transfer in the cask. 
The validation calculations comparing code results to analytical solutions presented in this report show that the conservation equations for mass, momentum, and energy are properly implemented in the code. The verification calculations comparing code results to experimental data from spent fuel storage casks show that the conservation equations in the code contain the appropriate physical models and constitutive relations to allow reasonably accurate calculations of the flow and heat transfer behavior in rod arrays, assemblies, and storage casks with complex designs. COBRA-SFS is fully applicable to transient analysis of spent fuel assemblies and storage casks. However, specific applications of the code should still be evaluated against experimental data where possible, and sensitivity studies should be performed to determine that the model represents the system accurately enough to produce reliable estimates of peak temperatures and other relevant performance measures. 


\section{Glossary}
A channel cross-sectional area $\left(\mathrm{ft}^{2}\right)$ in the axial direction
$\bar{A} \quad$ average cross-sectional area $\left(\mathrm{ft}^{2}\right)$ over the subchannel control volume
As surface area of slab node $\left(\mathrm{ft}^{2}\right)$
$c_{p} \quad$ specific heat at constant pressure $\left(\mathrm{Btu} / \mathrm{lbm}-{ }^{\circ} \mathrm{F}\right)$
$\mathrm{C}_{\mathrm{T}}$ turbulent momentum factor (dimensionless empirical parameter)
$D_{h} \quad$ hydraulic diameter of subchannel, based on wetted perimeter (ft)
$D_{\text {fuel }} \quad$ diameter of fuel (ft)
$\mathrm{D}_{\text {rod }} \quad$ outside diameter of fuel $\operatorname{rod}(\mathrm{ft})$
$d_{k} \quad$ diameter of $k$ th conduction heat transfer node in fuel or cladding ( $\mathrm{ft}$ )
$\mathrm{F}_{\mathrm{nm}} \quad$ grey body view factor from surface $\mathrm{n}$ to surface $\mathrm{m}$ for radiative heat transfer (dimensionless)
f axial friction factor, Darcy formulation (dimensionless)
g scalar gravitational acceleration constant, $\left(\mathrm{ft} / \mathrm{sec}^{2}\right)$
$\mathrm{g}_{c} \quad$ force/mass conversion constant for English engineering units, (32.2 lbm-ft/lbm-sec $\left.{ }^{2}\right)$
$\mathrm{H}_{\text {gap }} \quad$ conductance across the fuel-cladding gap (Btu/sec- $\left.\mathrm{ft}^{2}-{ }^{\circ} \mathrm{F}\right)$
$\mathrm{H}_{\text {surf }} \quad$ surface heat transfer coefficient (Btu/sec- $\mathrm{ft}^{2}-{ }^{\circ} \mathrm{F}$ )
h enthalpy (Btu/lbm)
K form drag for axial flow (dimensionless)
$\mathrm{K}_{G} \quad$ form drag for lateral flow (dimensionless)
$\mathrm{k}$ thermal conductivity (Btu/sec-ft- ${ }^{\circ} \mathrm{F}$ )
$\ell \quad$ centroid length for gap $\mathrm{k}(\mathrm{ft})$ 


\begin{tabular}{|c|c|}
\hline $\mathrm{m}$ & axial mass flow rate $(\mathrm{lbm} / \mathrm{sec})$ \\
\hline $\mathbf{P}$ & pressure (psia) \\
\hline$P_{w}$ & wetted perimeter of subchannel control volume ( $\mathrm{ft}$ ) \\
\hline$q^{\prime \prime}$ & surface heat flux (Btu/sec- $\left.\mathrm{ft}^{2}\right)$ \\
\hline$q^{\prime \prime \prime}$ & volumetric heat generation rate $\left(\mathrm{Btu} / \mathrm{sec}-\mathrm{ft}^{3}\right)$ \\
\hline $\operatorname{Re}$ & Reynolds number (dimensionless) \\
\hline$\dot{r}$ & internal heat generation rate per unit mass(Btu/lbm-sec) \\
\hline$S$ & width (ft) of gap $\mathrm{k}$ connecting channel ii to channel $\mathrm{jj}$ \\
\hline $\mathrm{T}$ & temperature $(\mathrm{F})$ \\
\hline $\mathrm{T}_{\text {clad }}$ & cladding surface temperature (F) \\
\hline $\mathrm{T}_{\mathrm{fs}}$ & temperature of the fuel surface $(F)$ \\
\hline$T_{i}$ & fluid temperature in current node of subchannel i (F) \\
\hline$T_{\text {fluid }}$ & average fluid temperature seen by rod $n(F)$ \\
\hline$T_{w}$ & wall surface temperature $(F)$ \\
\hline$T_{\text {wall }}$ & wall surface temperature $(\mathrm{F})$ \\
\hline U & scalar velocity (ft/sec) in the axial direction \\
\hline$\overline{\mathrm{U}}_{\mathbf{j}}$ & average axial velocity at $\mathrm{j}$ for momentum cell $(\mathrm{ft} / \mathrm{sec})$ \\
\hline $\mathbf{U}$ & composite thermal conductance (Btu/sec-F) \\
\hline $\mathrm{V}$ & scalar velocity in the lateral direction $(\mathrm{ft} / \mathrm{sec})$ \\
\hline$\overline{\mathrm{V}}_{\mathrm{k}}$ & average lateral velocity in gap $\mathrm{k}$ for momentum cell $(\mathrm{ft} / \mathrm{sec})$ \\
\hline w & mass flow rate in the lateral direction, per unit length $(\mathrm{lbm} / \mathrm{sec}-\mathrm{ft})$ \\
\hline
\end{tabular}


$w^{\prime} \quad$ turbulent crossflow for momentum and enthalpy exchange between adjacent channels $(\mathrm{lbm} / \mathrm{ft}-\mathrm{sec})$

$Z_{k} \quad$ empirical shape factor for conduction length of gap $k$ (dimensionless)

\section{Greek Symbols}

$\beta_{\mathrm{m}} \quad$ empirical mixing coefficient for turbulent crossflow model (dimensionless)

$\Delta \mathrm{X} \quad$ axial node length (ft)

$\Delta \mathrm{h} \quad$ change in enthalpy (Btu/lbm)

$\Delta r \quad$ radial increment in fuel noding $(\mathrm{ft})$

$\Delta \mathrm{U} \quad$ axial velocity difference between adjacent channels for turbulent mixing momentum exchange $(\mathrm{ft} / \mathrm{sec})$

$\Delta \mathrm{t} \quad$ transient time increment (sec)

$\theta \quad$ angle of channel axial orientation relative to vertical (degrees)

$\epsilon \quad$ surface emissivity of a solid node (dimensionless)

$\epsilon_{\mathrm{t}} \quad$ eddy diffusivity for turbulence $\left(\mathrm{ft}^{2} / \mathrm{sec}\right)$

$\mu \quad$ viscosity, $\left(\mathrm{lbm} / \mathrm{sec}-\mathrm{ft}^{2}\right)$

$\rho \quad \operatorname{density~}\left(\mathrm{lbm} / \mathrm{ft}^{3}\right)$

$\sigma \quad$ Stefan-Boltzmann constant; $4.76\left(10^{-13}\right)$ Btu/sec- $\mathrm{ft}^{2}-\mathrm{R}^{4}$

$\phi_{\mathrm{n}} \quad$ fraction of perimeter of rod $\mathrm{n}$ facing a given subchannel (dimensionless)

$\Sigma$

kei summation on all gaps $\mathrm{k}$ connected to channel $\mathrm{i}$

$\Sigma$

men summation on all channels $m$ facing $\operatorname{rod} n$

$\Sigma$

nei summation on all rods $n$ with heat transfer surfaces facing channel $i$ 
$\Sigma$

$\mathrm{n} \in \mathrm{k}$ summation on all gaps $\mathrm{n}$ connected to gap $\mathrm{k}$ for lateral momentum transport

$\Sigma$

$\mathrm{n} \in(\mathrm{N}+1)$ summation on all rod surface nodes $\mathrm{n}$ seen by cladding node $\mathrm{N}+1$

$\Sigma$

$m \in(N+1)$ summation on all slab nodes $m$ seen by cladding node $N+1$

\section{Subscripts}

c cladding material property

f fuel material property

ii lower-numbered channel of a pair connected by gap $k$

j axial level index number

$\mathrm{J} \quad$ axial level index for lateral momentum transport, (i.e., $\mathrm{J}=\mathrm{j}+1 / 2$ )

jj higher-numbered channel of a pair connected by gap $k$

k gap index number

s slab node property

w wall

$\theta \quad$ circumferential angle for radial fuel noding (radians)

\section{Superscripts}

n previous time-step value

$\mathrm{N} \quad$ current time step value

I" $\quad$ per unit cell quantity $\left(\mathrm{ft}^{3}\right)$

- donor cell quantity 


\section{Contents}

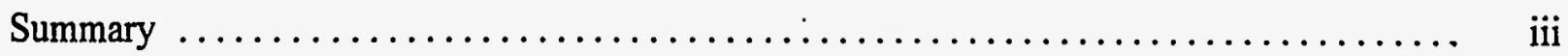

Glossary $\ldots \ldots \ldots \ldots \ldots \ldots \ldots \ldots \ldots \ldots \ldots \ldots \ldots \ldots \ldots \ldots \ldots \ldots \ldots \ldots \ldots \ldots \ldots \ldots$

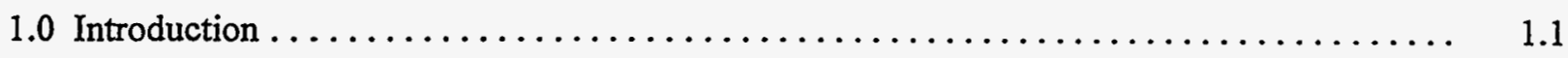

2.0 COBRA-SFS Code Description $\ldots \ldots \ldots \ldots \ldots \ldots \ldots \ldots \ldots \ldots \ldots \ldots \ldots \ldots \ldots \ldots \ldots \ldots \ldots \ldots \ldots$

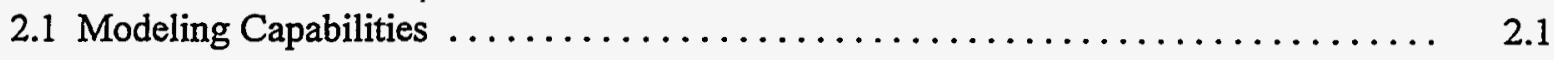

2.2 Conservation Equations in Finite Difference Form $\ldots \ldots \ldots \ldots \ldots \ldots \ldots \ldots \ldots$

2.2.1 Mass Continuity Equation $\ldots \ldots \ldots \ldots \ldots \ldots \ldots \ldots \ldots \ldots \ldots \ldots \ldots \ldots \ldots \ldots \ldots \ldots \ldots \ldots \ldots$

2.2.2 Fluid Energy Equation $\ldots \ldots \ldots \ldots \ldots \ldots \ldots \ldots \ldots \ldots \ldots \ldots \ldots \ldots \ldots \ldots \ldots \ldots \ldots \ldots \ldots$

2.2.3 Axial Momentum Equation $\ldots \ldots \ldots \ldots \ldots \ldots \ldots \ldots \ldots \ldots \ldots \ldots \ldots \ldots \ldots \ldots \ldots \ldots$

2.2.4 Transverse Momentum Equation $\ldots \ldots \ldots \ldots \ldots \ldots \ldots \ldots \ldots \ldots \ldots \ldots \ldots \ldots \ldots \ldots$

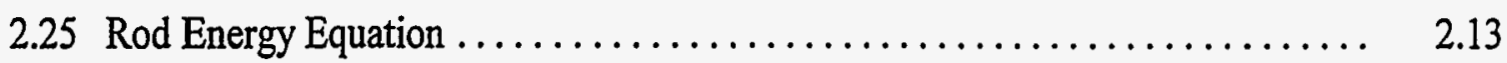

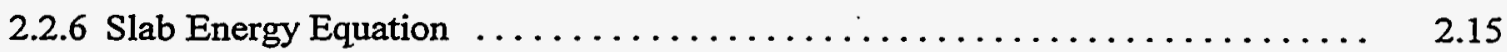

3.0 Transient Capability Verification $\ldots \ldots \ldots \ldots \ldots \ldots \ldots \ldots \ldots \ldots \ldots \ldots \ldots \ldots \ldots \ldots \ldots \ldots \ldots$

3.1 Transient Heat Transfer Solutions $\ldots \ldots \ldots \ldots \ldots \ldots \ldots \ldots \ldots \ldots \ldots \ldots \ldots \ldots \ldots \ldots \ldots$

3.1.1 Conduction in a Plate with Infinite Surface Heat Transfer Coefficient $\ldots \ldots \ldots \quad 3.2$

3.1.2 Conduction in a Plate with Nominal Surface Heat Transfer Coefficient ..... 3.6

3.1.3 Conduction in a Plate with Uniform Internal Heat Generation $\ldots \ldots \ldots \ldots \ldots .8$

3.1.4 Conduction in a Cylinder $\ldots \ldots \ldots \ldots \ldots \ldots \ldots \ldots \ldots \ldots \ldots \ldots \ldots \ldots \ldots \ldots \ldots$

3.2 Transient Flow Solutions $\ldots \ldots \ldots \ldots \ldots \ldots \ldots \ldots \ldots \ldots \ldots \ldots \ldots \ldots \ldots \ldots \ldots \ldots \ldots \ldots \ldots \ldots .13$

3.2.1 Transient Flow Between Two Parallel Plates $\ldots \ldots \ldots \ldots \ldots \ldots \ldots \ldots \ldots$

3.2.2 Transient Flow in a Pipe $\ldots \ldots \ldots \ldots \ldots \ldots \ldots \ldots \ldots \ldots \ldots \ldots \ldots \ldots \ldots \ldots \ldots \ldots \ldots .16$ 
4.0 Transient Capability Validation $\ldots \ldots \ldots \ldots \ldots \ldots \ldots \ldots \ldots \ldots \ldots \ldots \ldots \ldots \ldots \ldots \ldots \ldots \ldots \ldots \ldots \ldots$

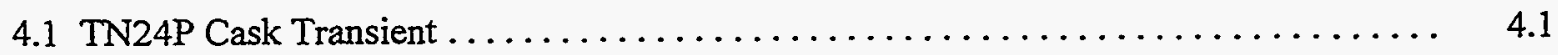

4.2 PSN/VSC-17 Cask Transient . . . . . . . . . . . . .

5.0 Conclusions and Recommendations $\ldots \ldots \ldots \ldots \ldots \ldots \ldots \ldots \ldots \ldots \ldots \ldots \ldots \ldots \ldots \ldots \ldots \ldots$

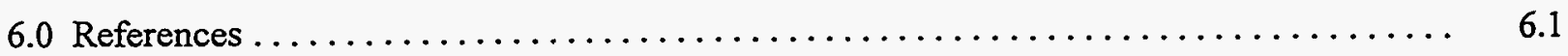




\section{Figures}

2.1 Relation of Subchannel Control Volume to Storage System $\ldots \ldots \ldots \ldots \ldots \ldots \ldots \ldots \ldots$

2.2 Subchannel Control Volume $\ldots \ldots \ldots \ldots \ldots \ldots \ldots \ldots \ldots \ldots \ldots \ldots \ldots \ldots \ldots \ldots \ldots \ldots \ldots$

2.3 Subchannel Computational Cell $\ldots \ldots \ldots \ldots \ldots \ldots \ldots \ldots \ldots \ldots \ldots \ldots \ldots \ldots \ldots \ldots$

3.1 Temperature Profiles in a Plate with Infinite Heat Transfer Boundary Condition;

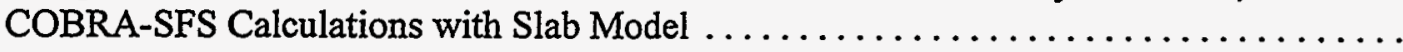

3.2 Centerline Temperature History Calculated with COBRA-SFS $\ldots \ldots \ldots \ldots \ldots \ldots \ldots$

3.3 Temperature Profiles in a Plate with Infinite Heat Transfer Boundary Condition;

COBRA-SFS Calculations with Subchannel Model .......................

3.4 Temperature Profiles in a Plate with Nominal Heat Transfer Boundary Condition;

COBRA-SFS Calculations with Slab Model $\ldots \ldots \ldots \ldots \ldots \ldots \ldots \ldots \ldots \ldots \ldots \ldots \ldots \ldots$

3.5 Temperature Profiles in a Plate with Uniform Heat Generation Rate; COBRA-SFS

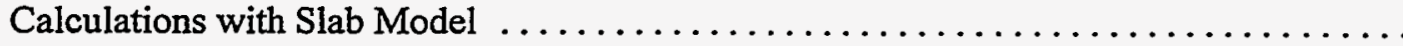

3.6 Temperature Profiles in a Cylinder with Infinite Heat Transfer Boundary Condition;

COBRA-SFS Calculations with Slab Model . . . . . . . . . . . . . . . . . . .

3.7 Temperature Profiles in a Cylinder with Infinite Heat Transfer Boundary Condition;

COBRA-SFS Calculations with Rod Model

3.8 Temperature Profiles in a Cylinder with Nominal Heat Transfer Boundary Condition;

COBRA-SFS Calculations with Rod Model

3.9 Velocity Profiles for Flow Between Two Parallel Plates; COBRA-SFS Calculations with Zero-Slip at the Wall Boundary Condition $\ldots \ldots \ldots \ldots \ldots \ldots \ldots \ldots$

3.10 Average Velocity Evolution for Transient Flow in a Pipe; COBRA-SFS Calculations with Zero-Slip at the Wall Boundary Condition and for Subchannel Model with Empirical

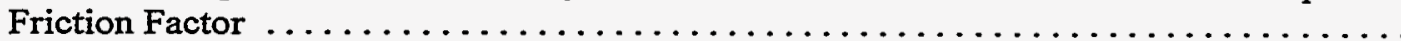

4.1 TN24P PWR Spent Fuel Storage Cask $\ldots \ldots \ldots \ldots \ldots \ldots \ldots \ldots \ldots \ldots \ldots \ldots \ldots \ldots \ldots$

4.2 TN24P PWR Spent Fuel Storage Cask Cross-Section $\ldots \ldots \ldots \ldots \ldots \ldots \ldots \ldots \ldots \ldots$

4.3 TN24P Transient: Backfill Changed from Helium to Air--Comparison of COBRA-SFS Calculations to Measurements from TC Lance D1-5 
4.4 Diagram of PSN/VSC-17 Cask Structure

4.5 PSN/VSC-17 Transient: All Vents Closed Changed to All Vents Open, with Helium Backfill--Comparison of COBRA-SFS Calculations with Measurements from

TC Lance L6, Thermocouple \#3 


\section{Tables}

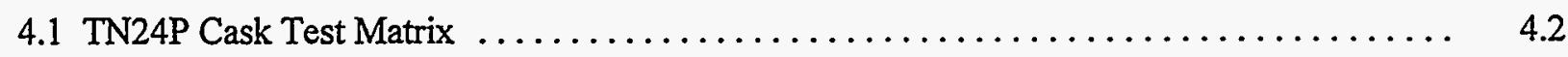

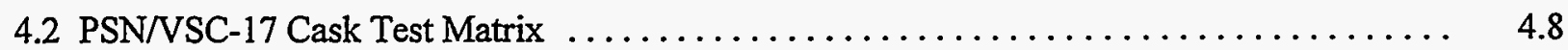




\subsection{Introduction}

This report provides documentation of the verification and validation testing of the transient capability in the COBRA-SFS code, and is organized into three main sections. The primary documentation of the code was published in September 1995, with the release of COBRA-SFS, Cycle 2. The validation and verification supporting the release and licensing of COBRA-SFS was based solely on steady-state applications, even though the appropriate transient terms have been included in the conservation equations from the first cycle.

Section 2.0, COBRA-SFS Code Description, presents a capsule description of the code, and a summary of the conservation equations solved to obtain the flow and temperature fields within a cask or assembly model. This section repeats in abbreviated form the code description presented in the primary documentation (Michener et al. 1995), and is meant to serve as a quick reference, rather than independent documentation of all code features and capabilities. Section 3.0, Transient Capability Verification, presents a set of comparisons between code calculations and analytical solutions for selected heat transfer and fluid flow problems. Section 4.0, Transient Capability Validation, presents comparisons between code calculations and experimental data obtained in spent fuel storage cask tests.

Based on the comparisons presented in Sections 2.0 and 3.0, conclusions and recommendations for application of COBRA-SFS to transient analysis are presented in Section 5.0. 


\subsection{COBRA-SFS Code Description}

COBRA-SFS (Spent Fuel Storage), is a computer program for thermal-hydraulic analyses of multiassembly spent-fuel storage and transportation systems (Rector et al. 1986a, Lombardo et al. 1986a, Rector and Michener 1989). The code uses a lumped parameter finite-difference approach to predict flow and temperature distributions in spent fuel storage systems and fuel assemblies under forced and natural convection heat transfer conditions in both steady-state and transients. It is derived from the COBRA family of codes (Rowe 1973, Stewart et al. 1977, George et al. 1980, Khan et al. 1981), which have been extensively evaluated against in-pile and out-of-pile data. COBRA-SFS retains all the important features of the COBRA codes for single-phase analysis, and extends the range of application to problems with two-dimensional radiative and three-dimensional conductive heat transfer. With these added capabilities, COBRA-SFS has been used to analyze various single- and multi-assembly spent fuel storage systems containing intact and consolidated fuel with a variety of fill media.

COBRA-SFS solves the equations governing mass, momentum, and energy conservation for incompressible flows in finite-difference form. A subchannel approach is used, in which flow areas of rod arrays, assemblies or storage systems are divided into discrete control volumes for which conservation of mass, momentum, and energy is applied. The conservation equations are solved using an iterative implicit method. The energy equations for the coolant, rod cladding, fuel, and structural members (referred to as slabs) are solved implicitly by iteration in the axial direction and simultaneously in a plane. Axial conduction in the structural members is included. Additionally, a nonparticipating media gray body radiative heat transfer model allows two-dimensional radiant heat exchange between solid materials. This model is iteratively coupled to the rod and wall energy equations.

The flow field can either be defined as a boundary condition or calculated internally as a function of the gravitational and dynamic pressure losses. Heat loss from the boundary can vary circumferentially or axially or both, and can include both radiative and convective heat transfer. Axial heat transfer from the subchannel region to plenum regions (i.e., regions above and below the fuel assemblies) can also be modeled. The COBRA-SFS modeling capabilities and the conservation equations are described briefly in the following subsections. For a detailed description of the derivation of the conservation equations, and the assumptions and approximations used in the code, refer to the primary documentation of Cycle 2 (Michener et al. 1995).

\subsection{Modeling Capabilities}

COBRA-SFS allows simulations of a wide range of dry storage systems. In addition to the multiassembly cask analysis described in this report, applications have included analyses of single-assembly spent fuel storage systems with multiple orientations and fill media, multi-assembly systems with unconsolidated spent fuel, and analyses of both single- and multi-assembly consolidated fuel storage systems (Cuta et al. 1984, Lombardo et al. 1986b, Cuta and Creer 1986, Wiles et al. 1986, Rector et al. 1986b, Rector et al. 1986c, McKinnon et al. 1989, Wheeler et al. 1986). This is accomplished in 
COBRA-SFS by formulating the governing equations for flow of a single-component mixture on an arbitrary fixed Eulerian control volume (Slattery 1972). Integral balances for mass, energy, and linear momentum are formed on the arbitrary Eulerian control volume, then applied to subchannel modeling with appropriate definitions and simplifications, and converted to partial differential equations over the subchannel control volume. The resulting system of subchannel equations is then expressed in finitedifference form, and can be solved numerically for the flow and temperature fields.

The basic Eulerian control volume in COBRA-SFS is the fluid subchannel in the rod array. Fluid flow is constrained by the surfaces of the closely spaced fuel rods, and the fuel rods partition the flow area into many subchannels that communicate laterally by crossflow through the narrow gaps between the rods. This geometry is illustrated in Figure 2.1, which shows the subchannel in relation to the assembly. This approach can also be generalized to apply to large regions of the flow field, wherein a single channel can represent a large number of individual subchannels in a fuel rod array, or large open regions that do not contain fuel rods within a storage cask (refer to Michener et al. 1995; specifically, Part II-User Guide, for a more complete discussion).

An example of a subchannel control volume is shown in Figure 2.2, where A denotes the axial area for flow, $U$ denotes the velocity of flow in the axial direction, and $\mathrm{V}$ is the velocity of transverse flow through the gaps between the fuel rods forming the subchannel. This subchannel has three gaps, each of which with a transverse flow area given by $\mathrm{S} \Delta \mathrm{X}$. Assuming linear variation in $\mathrm{A}$ over axial distance, (i.e., the distance along the main axis of the rod bundle), the volume, $V$, of the subchannel control volume is given by

$$
\mathrm{V}=\overline{\mathrm{A}} \Delta \mathrm{X}
$$

where $=1 / 2\left(A_{X}+A_{X+\Delta X}\right)$

The total fluid surface $\mathrm{F}$ of the control volume consists of the axial flow area $\mathrm{A}$ at the top and bottom of the control volume, plus the transverse flow areas of the gaps between the fuel rods, $S_{k} \Delta X$. The solid surface $\underline{W}$ of the control volume is defined by the surfaces of the rods forming the subchannels. The flow field is assumed to be space- and time-averaged in such a way that the quantities of interest, $(p, \rho U, \rho V$, $\mathrm{ph}$ ), have continuous derivatives, and the volume and surface averages are defined in terms of the volume and surface integrals.

Closure of the equation set is achieved by means of empirical relations for momentum exchange due to wall friction, form drag, and turbulent mixing in the fluid flow equations for mass and momentum continuity. In the energy equations, empirical heat transfer correlations are used to define heat transfer between rods or walls and the fluid. Constitutive relations can also be specified for contact conductance between solid nodes that are in physical contact. Radiative heat transfer is modeled by specifying radiative exchange factors based on geometric view factors. 


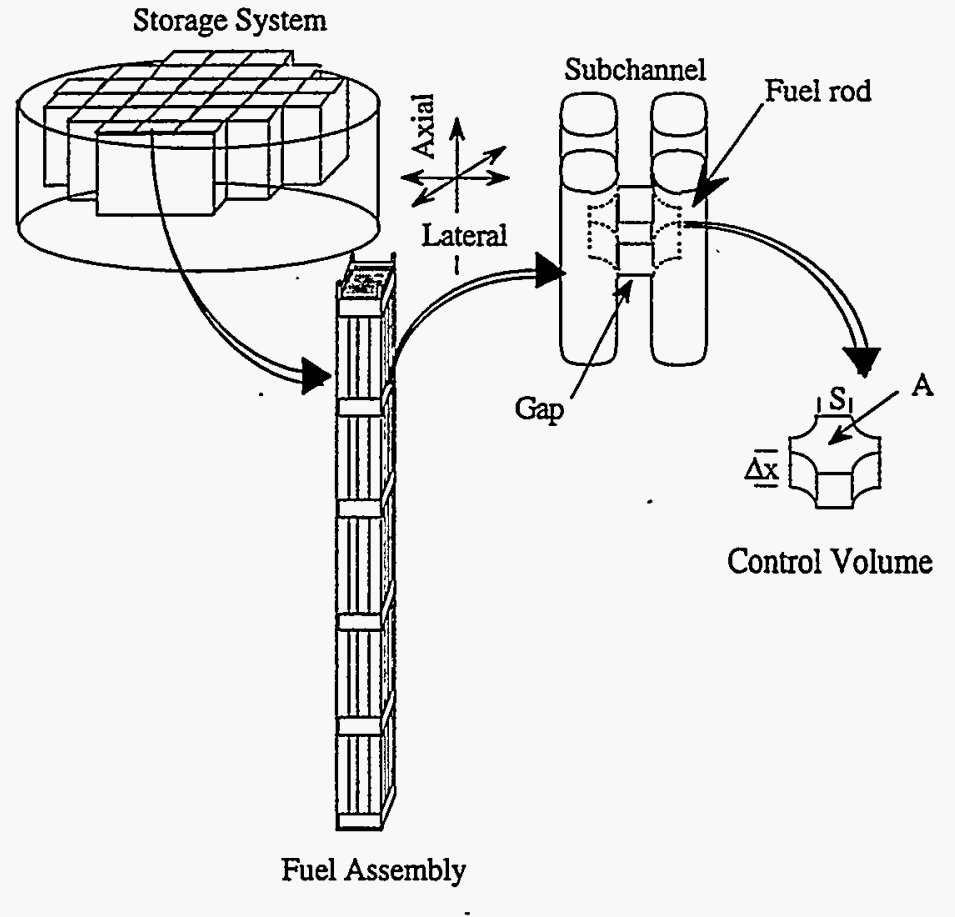

Figure 2.1. Relation of Subchannel Control Volume to Storage System

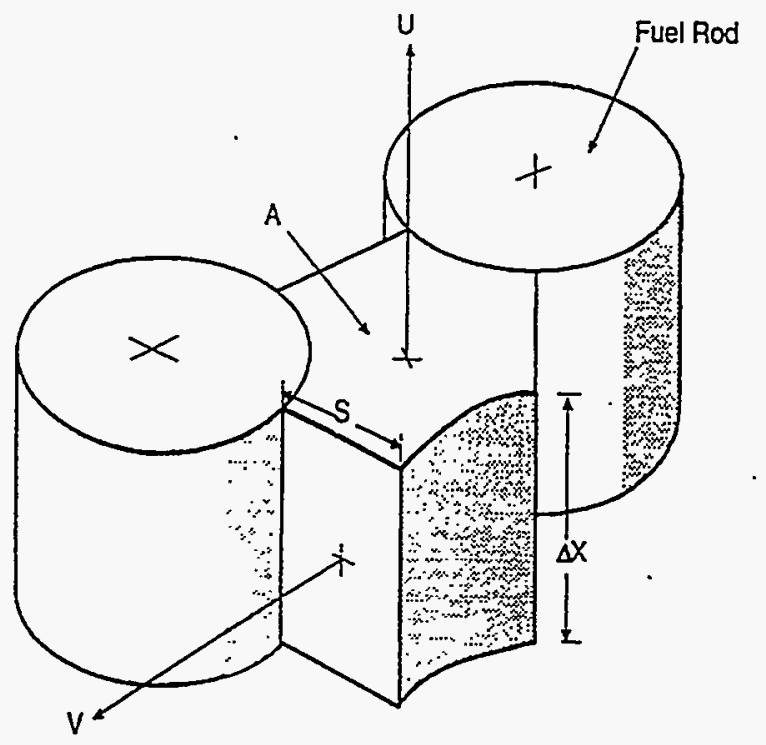

Figure 2.2. Subchannel Control Volume 
The code can be used for steady-state or transient calculations in geometries consisting of intact rod arrays on square or triangular pitch. Consolidated rod arrays can also be modeled, as a special case of triangular pitch with zero (or very small) gaps between the rods. The code can model mixed geometries; that is, the same case can contain some assemblies modeled as subchannels and rods, others modeled as lumped channels and rods, still others as open regions without rods. Axial variations in the geometry, such as variable axial grid spacing, multiple non-uniform axial power distributions, and non-uniform fuel material properties can be specified by input. Inter- and intra-assembly heat transfer is readily modeled, including both convection and conduction heat transfer, and two fluid properties tables can be specified, so that different assemblies can have different fluid properties.

Boundary conditions can be specified in a number of different ways, allowing great flexibility for various applications of the code. These features include the following

- recirculating flows

- zero net flow solution

- multiple flow regions

- fluid conduction and turbulent mixing

- pressure drop model

- variable property rod model

- specified heat flux

- plenum heat flux (optional).

Radiation heat transfer is calculated in two dimensions assuming a nonparticipating media. The user has the option of supplying black body view factors, in which case the code will calculate the corres-. ponding grey-body view factors for the surfaces. For rod arrays, the user can specify the grey body view factors using an additional input file, tape 10 , created using the auxiliary code RADGEN.

The COBRA-SFS code contains control features and boundary condition options to enhance its usability for the detailed and complicated calculations required for analysis of storage casks. These include the following

- constant specified flow

- restart and post-processing data dump 
- decoupled hydrodynamics (i.e., option to specify no buoyancy)

- pressure drop initialization scheme.

The main limiting assumptions in the code are that the fluid is undergoing incompressible flow and that heat transfer at the boundary is in one direction only for a given node. 


\subsection{Conservation Equations in Finite Difference Form}

The subchannel partial differential equations for mass continuity, fluid energy conservation, and momentum conservation are approximated as finite difference equations for solution in the code. These equations can be used to model any flow field that can be adequately represented as a set of parallel channels with predominantly axial flow that communicate through transverse flow paths connecting the channels. The only requirement is that the assumptions and simplifications of subchannel modeling are not violated.

The finite difference equations are developed for a generalized control volume represented by the computational cell shown in Figure 2.3, with the computational variables located as shown. The state variables of density $(p)$ and enthalpy $(h)$ are defined at the cell center and are indexed by the node number. The axial flow rate ( $m=\rho$ * $U A$ ), the pressure $(P)$ and axial flow area $(A)$ are defined at the upper and lower cell boundaries, and are indexed by the corresponding axial levels, $j$ and $j-1$. For a given gap $k$, the gap width $\left(S_{k}\right)$ and the crossflow per unit length $\left(w=p^{*} V S_{k}\right)$, are defined on the transverse cell boundary midway between the axial levels, indexed by the gap number and axial level of the upper face (j) of the cell.

The positive direction for the axial velocity (U) is the direction from the channel inlet to the exit, along the main axis of the fuel rods. For conventional application to vertically oriented fuel bundles, this is the upward flow direction. Negative axial velocities define flow in the opposite direction. The sign convention on the transverse velocity does not have such a convenient reference as gravity, and is defined by convention. The transverse velocity in gap $k\left(V_{k}\right)$ is positive when flow is from the lowernumbered subchannel (denoted ii) of the pair forming the gap into the higher-numbered channel (denoted ji) of the pair. The velocity is negative if flow is in the opposite direction. This convention is implemented by means of the unitary switch function, $e_{i k}$, which is applied as a multiplier on terms containing the transverse velocity. It is defined for gap $k$ such that

$$
\begin{array}{ll}
e_{i k}=1.0, & \text { if } i=i i \\
e_{i k}=-1.0, & \text { if } i=j j
\end{array}
$$

The finite difference equations are derived from the subchannel conservation equations in partial differential form by approximating the time derivative with the time step $\Delta t$, and the spatial derivative with the axial noding increment $\Delta \mathrm{X}$. The results of this procedure are shown for the conservation equations in the following subsections. 


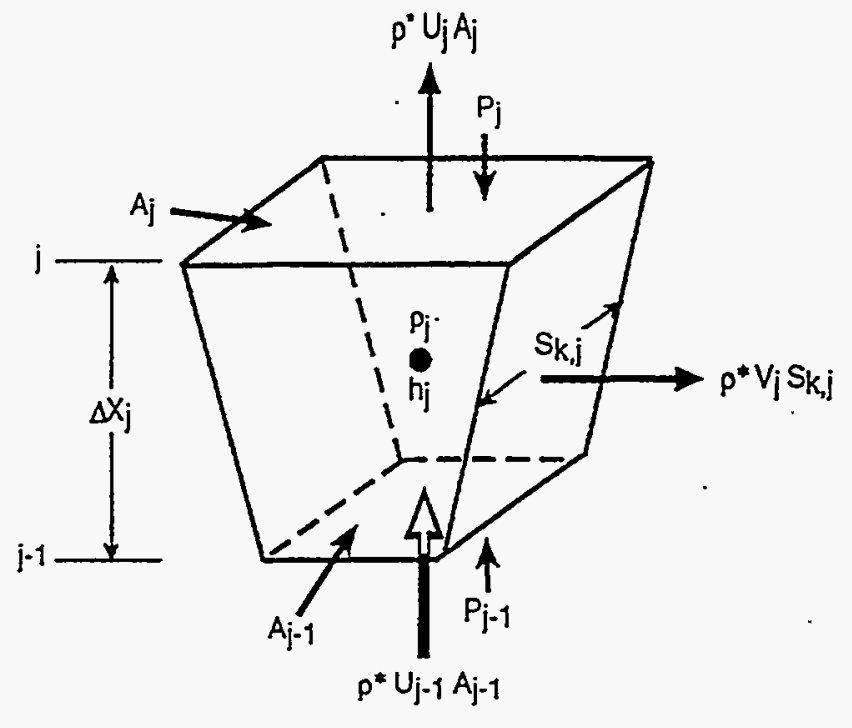

Figure 2.3. Subchannel Computational Cell 


\subsubsection{Mass Continuity Equation}

The assumptions made in the derivation of the continuity equation are that the channel area changes linearly with distance over the length of the control volume, the fluid density is uniform throughout the control volume, the axial and transverse velocities are uniform over the respective areas, and the transverse connection width is constant over the length of the control volume. The final form of the equation for conservation of mass in the COBRA-SFS code is

$$
\bar{A}_{j} \frac{\Delta X_{j}}{\Delta t}\left(\rho-\rho^{2}\right)_{j}+m_{j}-m_{j-1}+\Delta X_{j} \sum_{k \in i} e_{i k} w_{k}=0
$$

\subsubsection{Fluid Energy Equation}

The finite difference approximation of the subchannel equation for fluid energy can be written directly from the subchannel equation using the definitions and assumptions noted above for the mass conservation equation. The finite difference form of the energy equation is, therefore,

$$
\begin{aligned}
& \bar{A}_{j} \Delta x_{j} \frac{\left(\rho h-(\rho h)^{n}\right)_{j}}{\Delta t}+m_{j} h^{*}-m_{j-1} h^{*} \\
& +\Delta x_{j} \sum_{k \in i} e_{i k} w_{j} h^{*}=\sum_{n \in i} P_{w} \phi_{n} \Delta x_{j} q^{\prime \prime} \\
& +\sum_{k \in i} e_{i k} s_{j} \Delta x_{j} \bar{k} \frac{\left(T_{i j}-T_{i j}\right)_{j}}{\ell Z_{k}}+\Delta x_{j} \sum_{k \in i} e_{i k} \bar{w}_{j}^{\prime}\left(h_{i i}-h_{i j}\right)_{j}
\end{aligned}
$$

In the solution of the energy equation in COBRA-SFS, the mass continuity error is separated from the energy error by multiplying the mass continuity equation by the flowing enthalpy and subtracting the result from the energy equation. The final form of the finite difference equation for the fluid energy in COBRA-SFS is therefore,

$$
\begin{aligned}
& \bar{A}_{j} \Delta X_{j} \frac{\left(\rho h-(\rho h)^{\mathrm{n}}\right)_{j}}{\Delta t}+m_{j}\left(h^{*}-h_{j}\right)-m_{j-1}\left(h^{*}-h_{j-1}\right) \\
& +\Delta x_{j} \sum_{k \in i} e_{i k} w_{j}\left(h^{*}-h_{j}\right)=\sum_{n \in i} P_{w} \phi_{n} \Delta x_{j} q^{\prime \prime} \\
& +\sum_{k \in i} e_{i k} S_{j} \Delta X_{j} \bar{k} \frac{\left(T_{i i}-T_{i j}\right)_{j}}{\ell Z_{k}}+\Delta X_{j} \sum_{k \in i} e_{i k} w_{j}^{\prime}\left(h_{i i j}-h_{i j}\right)_{j}
\end{aligned}
$$


The heat flux through the solid surfaces of the control volume, denoted by q" in Equation (2.3), is the surface-averaged convective heat flux over the given node. If the conduction model is not used, the heat flux is simply a boundary condition specified by user input. When the conduction model is used, the heat flux is a calculated quantity determined in the solution of the conduction equation for heat transfer in the fuel rods or solid structure nodes, (as described in Section 2.2.5 or 2.2.6, below.) Heat transfer between the fluid and a rod or wall is modeled using empirical heat transfer coefficients, such that

$$
\mathrm{q}^{\prime \prime}=\mathrm{H}_{\text {surf }}\left(\mathrm{T}_{\mathrm{w}}-\mathrm{T}\right)
$$

The surface temperature of the rod or slab node $\left(\mathrm{T}_{\mathrm{w}}\right)$ is solved for in the solid conduction energy equation. The sink temperature $T$ for the heat flux calculation is the fluid temperature corresponding to the enthalpy of the subchannel at that node.

\subsubsection{Axial Momentum Equation}

The time and space derivatives for the flow rates can be approximated for the momentum equations in the same way as for the mass continuity equation. The derivative of the pressure is approximated by assuming a linear pressure variation. Appropriate averaging across node boundaries must be defined for the axial and transverse convection of axial momentum. For the axial convection of axial momentum, the transporting velocity is the velocity at the cell center, which is defined as the average of the velocity at $j$ and $j+1$, such that

$$
\bar{U}_{j}=\frac{\frac{1}{2}\left(m_{j}+m_{j+1}\right)}{\frac{1}{2}\left(\rho_{j}+\rho_{j+1}\right) \frac{1}{2}\left(\bar{A}_{j}+\bar{A}_{j+1}\right)}
$$

This velocity convects either $m_{j}$ or $m_{j+1}$, depending on its direction, so that

$$
\bar{U}_{j} m= \begin{cases}\bar{U}_{j} m_{j} & \text { if } \bar{U}_{j} \geq 0 \\ \bar{U}_{j} m_{j+1} & \text { if } \bar{U}_{j}<0\end{cases}
$$

Similarly, for the transverse transport of axial momentum the transporting velocity is the transverse velocity at the cell boundary. This is obtained by averaging the crossflows at $j$ and $j+1$, such that 


$$
\bar{V}_{k, j}=\frac{\frac{1}{2}\left(w_{j}+w_{j+1}\right)}{\frac{1}{2}\left(\bar{\rho}_{k, j}+\bar{\rho}_{k, j+1}\right) \frac{1}{2}\left(s_{k, j}+S_{k, j+1}\right)}
$$

The average density at $\mathrm{j}$ and $\mathrm{j}+1$ used in this relation is defined as

$$
\bar{\rho}_{k}=\frac{1}{2}\left(\rho_{\mathrm{ii}}+\rho_{\mathrm{jj}}\right)
$$

The average transverse velocity convects the axial momentum at $\mathrm{j}$ of either channel ii or $\mathrm{jj}$, depending on its sign. The $\Delta U$ term in the turbulent momentum exchange must also be defined, using appropriate averaging to obtain the axial velocities at a given level. For channel $i$ (which may be either ii and $\mathrm{jj}$ ) at level $\mathrm{j}$, the average axial velocity is given by

$$
\begin{aligned}
& \qquad \bar{U}_{i}=\frac{m_{i}}{\bar{\rho}_{i} A_{i}} \\
& \text { where } \quad \bar{\rho}_{i}=\frac{1}{2}\left(\rho_{j}+\rho_{j+1}\right)
\end{aligned}
$$

Using this definition, the turbulent crossflow exchange can be expressed as

$$
\sum_{\mathbf{k} \in \mathrm{i}} e_{\mathrm{ik}} w^{\prime}\left(\frac{\mathrm{m}_{\mathrm{ii}}}{\overline{\bar{\rho}}_{\mathrm{ii}} \mathrm{A}_{\mathrm{ii}}}-\frac{\mathrm{m}_{\mathrm{jj}}}{\overline{\bar{\rho}}_{\mathrm{ij}} \mathrm{A}_{\mathrm{ij}}}\right) \mathrm{C}_{\mathrm{T}} \Delta \mathrm{x}
$$

The turbulent crossflow transports both momentum and energy from one channel to the other, but produces no net mass exchange between adjacent channels.

When the above definitions and approximations are used in the subchannel equation for axial momentum, the finite difference form of the axial momentum equation is 


$$
\begin{aligned}
& \frac{\Delta x_{j}\left(m_{j}-m_{j}{ }^{n}\right)}{\Delta t}+m_{j}^{*} \bar{U}_{j}-m_{j-1}^{*} \bar{U}_{j-1}+\sum_{k \in i}\left[e_{i k}\left(\frac{m}{A}\right)_{k}^{*} \bar{V}_{k} s_{k}\right]_{j} \Delta x_{j} \\
& +\sum_{k \in i} e_{i k} w_{k}\left(\frac{m_{i i}}{\bar{\rho}_{i i} A_{i i}}-\frac{m_{j j}}{\bar{\rho}_{i j} A_{i j}}\right) C_{T} \Delta x_{j}=\bar{A}_{j} g_{c}\left(P_{j-1}-P_{j}\right) \\
& \quad-\Delta x_{j} \bar{A}_{j} \rho_{j} g \cos \theta-\frac{1}{2}\left(\frac{f}{D_{h}}+\frac{K}{\Delta x_{j}}\right) \Delta x_{j}\left|\frac{m_{j}}{\rho_{j} A_{j}}\right| m_{j}
\end{aligned}
$$

In applications where fluid-fluid shear must be included in the axial momentum equation, the wall shear stress term cannot be represented empirically. It is treated by specifying zero slip at the wall, and the finite difference form in this case is expressed as follows

$$
\begin{aligned}
& \frac{\Delta x_{j}\left(m_{j}-m_{j}{ }^{n}\right)}{\Delta t}+m_{j}^{*} \bar{U}_{j}-m_{j-1}^{*} \bar{U}_{j-1}+\sum_{k \in i}\left[e_{i k}\left(\frac{m}{A}\right)_{k}^{*} \bar{V}_{k} s_{k}\right]_{j} \Delta x_{j} \\
& +\sum_{k \in i} e_{i k} w_{k}\left(\frac{m_{i i}}{\bar{\rho}_{i j} A_{i i}}-\frac{m_{i j}}{\bar{\rho}_{j j} A_{i j}}\right) C_{T} \Delta x_{j}=\bar{A}_{j} g_{c}\left(P_{j-i}-P_{j}\right) \\
& -\Delta x_{j} \bar{A}_{j} \rho_{j} g \cos \theta-\sum_{k \varepsilon i} e_{i k}\left(U_{i i}-U_{j j}\right) \frac{S}{l} \mu_{k} \Delta x_{j}-\mu \frac{P_{w}}{\ell} U_{j} \Delta x_{j}
\end{aligned}
$$

\subsubsection{Transverse Momentum Equation}

As with the axial momentum equation, average velocities for momentum transport must be defined in order to formulate the finite difference equation. In the axial convection of transverse momentum, the transporting velocity is defined as

$$
\bar{U}_{j}=\frac{1}{\left(A_{i i}+A_{i j}\right)}\left(\frac{m_{i i}}{\bar{\rho}_{i i}}+\frac{m_{i j}}{\bar{\rho}_{i j}}\right)
$$

The crossflow convected by this average velocity defines the transport term as

$$
\bar{U}_{j} w^{*}=\left\{\begin{array}{l}
\bar{U}_{j} w_{j} \text { if } \bar{U}_{j} \geq 0 \\
\bar{U}_{j} w_{j+1} \text { if } \bar{U}_{j}<0
\end{array} .\right.
$$


The final form of the finite difference equation for transverse momentum becomes

$$
\begin{gathered}
\Delta x_{j}\left(\frac{w_{j}-w_{j}^{n}}{\Delta t}\right)+w_{j}^{*} \bar{U}_{j}-w_{j-1}^{*} \bar{U}_{j-1}=\frac{s_{j} \Delta x_{j}}{\ell} g_{c}\left(P_{i i}-P_{i j}\right)_{j-1} \\
-s_{j} \ell \Delta x_{j} \bar{\rho}_{j} g \sin \theta-\frac{1}{2} K_{G}\left|\frac{w_{j}}{\bar{\rho}_{j} S_{j}}\right| w_{j} \frac{\Delta x_{j}}{\ell}
\end{gathered}
$$

In applications where fluid-fluid shear must be included in the transverse momentum equation, the finite difference form must include the additional fluid shear stress terms,

$$
\mathrm{F}_{\text {lateral terms }}=\mathrm{F}_{\mathrm{axl}}+\mathrm{F}_{\text {lat }}
$$

The axial transport of transverse momentum, $\mathrm{F}_{\mathrm{axl}}$, is defined as

$$
F_{a x l}=-S \ell\left[2 \mu_{j-1} \frac{V_{j}-v_{j-1}}{\Delta X_{j}+\Delta X_{j+1}}+2 \mu_{J} \frac{v_{j}-V_{j+1}}{\Delta X_{j}+\Delta X_{j+1}}\right]
$$

The viscosities are calculated by averaging between the values of the adjacent channels connected by the gap at the axial levels $\mathrm{j}$ and $\mathrm{j}-1$, and at $\mathrm{j}$ and $\mathrm{j}+1$.

The lateral transport of transverse momentum, $\mathrm{F}_{\text {lat }}$ is defined as

$$
F_{\text {lat }}=-\sum_{n \in k} \ell \Delta x_{j} \bar{\mu}\left[\frac{2\left(V_{k}-V_{n}\right)}{S_{k}+S_{n}}\right]
$$

In the summation, $\mathrm{n}$ is the index of a gap connected to gap $\mathrm{k}$ by fluid-fluid shear. The average viscosity is calculated at a given axial level as

$$
\bar{\mu}=\frac{1}{4}\left[\mu_{\mathrm{ii}, \mathrm{k}}+\mu_{\mathrm{ij,k},}+\mu_{\mathrm{ii,n}}+\mu_{\mathrm{j}, \mathrm{I}}\right]
$$


The $F_{\text {lateral terms }}$ defined above are substituted into the transverse momentum equation for the case with fluid-fluid shear. The finite difference form is therefore expressed as follows:

$$
\begin{aligned}
& \Delta X_{j}\left(\frac{w_{j}-w_{j}{ }^{2}}{\Delta t}\right)+w_{j}^{*} \bar{U}_{j}-w_{j-1}^{*} \bar{U}_{j-1}=\frac{s_{j} \Delta X_{j}}{l} g_{c}\left(P_{i i}-P_{i j}\right)_{j-1} \\
& -S_{j} l \Delta X_{j} \bar{\rho}_{j} g \sin \theta-\frac{1}{2} K_{G}\left|\frac{w_{j}}{\bar{\rho}_{j} S_{j}}\right| w_{j} \frac{\Delta X_{j}}{\ell} \\
& -s \ell\left[2 \mu_{j-1} \frac{V_{j}-v_{j-1}}{\Delta x_{j}+\Delta x_{j+1}}+2 \mu_{j} \frac{v_{j}-v_{j+1}}{\Delta x_{j}+\Delta x_{j+1}}\right] \\
& -\sum_{n \ell k} \ell \Delta x_{j} \bar{\mu}\left[\frac{2\left(V_{k}-v_{n}\right)}{S_{k}+S_{n}}\right]
\end{aligned}
$$

\subsubsection{Rod Energy Equation}

In steady state calculations, the heat generation in the fuel rods can be treated as a simple heat flux boundary condition on the fluid, and it is not necessary to solve the conduction equation for the fuel rods. Even in cases involving radiative heat transfer, where it is necessary to determine the surface temperatures of the fuel rods, a simplified form of the rod energy equation can be used, in which the conduction equation is solved for the cladding only, treating the heat generated in the fuel as a source term at the inner boundary. In transient calculations, however, it is necessary to use the complete rod energy equation, including the time-dependent terms in all nodes of the fuel rod. The conduction equation for the cladding is

$$
\begin{aligned}
& A_{c} \Delta X_{j} \rho_{c} c_{p} \frac{T_{\text {clad }}-T_{c l a d}{ }^{n}}{\Delta t}=-\Delta x_{j} \sum_{n \in i}\left(\pi D_{\text {rod }}\right) \phi_{n} H_{\text {surf }}\left(T_{c l a d}-T_{i}\right) \\
& -\Delta X_{j} \sum_{n \in m}\left(\pi D_{\text {rod }}\right) \sigma F_{n m}\left(T_{\text {clad }_{n}}^{4}-T_{\text {elad }_{n}}{ }^{4}\right) \\
& -\Delta \mathrm{X}_{\mathrm{j}} \sum_{\mathrm{n} \in \mathrm{m}}\left(\pi \mathrm{D}_{\text {rod }}\right) \sigma \mathrm{F}_{\mathrm{mn}}\left(\mathrm{T}_{\text {clad }_{\mathrm{n}}}{ }^{4}-\mathrm{T}_{\text {wall }_{\mathrm{g}}}{ }^{4}\right)+\left(\pi \mathrm{D}_{\text {fuel }}\right) \mathrm{H}_{\mathrm{gap}}\left(\mathrm{T}_{\text {clad }}-\mathrm{T}_{\mathrm{fs}}\right)
\end{aligned}
$$

The clad conduction equation is coupled to the fuel conduction equation through the gap heat transfer coefficient $\left(\mathrm{H}_{\mathrm{gap}}\right)$ and the temperature difference across the gap between the fuel pellet and the clad. The gap heat transfer coefficient is an empirical parameter, defined by user input. In the clad node, heat transfer is considered in the radial direction only. In the fuel pellet, the conduction equations are 
formulated to allow the option of considering azimuthal as well as radial noding. Nodes in the circumferential direction are counted with the variable $\mathrm{N}_{\theta}$, and in the radial direction with $\mathrm{N}$ in the following equations. The fuel pellet node temperatures are identified as $T_{k, m}$ where $k$ is the radial location ( 1 to $N$ ), and $m$ is the circumferential location $\left(1\right.$ to $N_{\theta}$ ). The set of conduction equations in finite-difference form for each of the $\mathrm{N}$ fuel nodes and the cladding node, $\mathrm{N}+1$, can be written as shown in Equation (2.9) through (2.12) below.

In this model, it is assumed that axial heat transfer is negligible, heat is generated uniformly throughout the fuel pellet at a given axial location, and material properties of the fuel do not vary significantly with the radial variation in temperature.

Fuel Node 1 (inner-most node):

$$
\begin{aligned}
& \pi\left(\frac{d_{2}^{2}-d_{v o i d}^{2}}{4 N_{\theta}}\right) \rho_{f} c_{p_{f}} \frac{T_{1, m}-T_{1, m}^{n}}{\Delta t}+\frac{\pi d_{2}}{\Delta r N_{\theta}} k_{f}\left(T_{1, m}-T_{2, m}\right) \\
& +\frac{2 \Delta r N_{\theta}}{\pi\left(d_{1}+d_{2}\right)} k_{f}\left(2 T_{1, m}-T_{1, m-1}-T_{1, m+1}\right) \\
& =q_{f}^{\prime \prime \prime} \pi\left(\frac{d_{2}^{2}-d_{1}^{2}}{4 N_{\theta}}\right)+\frac{\pi}{N_{\theta}} d_{i} q_{\text {void }}^{*}
\end{aligned}
$$

Fuel Nodes 2 Through N-1:

$$
\begin{aligned}
& \pi\left(\frac{d_{k+1}^{2}-d_{k}^{2}}{4 N_{\theta}}\right) \rho_{f}^{c} c_{p_{f}} \frac{T_{k, m}-T_{k, m}^{n}}{\Delta t}+\frac{\pi d_{k}}{\Delta r N_{\theta}} k_{f}\left(T_{k, m}-T_{k-1, m}\right) \\
& +\frac{\pi d_{k+1}}{\Delta r N_{\theta}} k_{f}\left(T_{k, m}-T_{k+1, m}\right) \\
& +\frac{2 \Delta r N_{\theta}}{\pi\left(d_{k}+d_{k+1}\right)} k_{f}\left(2 T_{k, m}-T_{k, m-1}-T_{k, m+1}\right)=q_{f}^{\prime \prime \prime} \pi\left(\frac{d_{k+1}^{2}-d_{k}^{2}}{4 N_{\theta}}\right)
\end{aligned}
$$




\section{Fuel Node $\mathbf{N}$ (fuel surface node):}

$$
\begin{aligned}
& \pi\left(\frac{d_{\text {fuel }}^{2}-d_{N}^{2}}{4 N_{\theta}}\right) \rho_{f} c_{p_{f}} \frac{T_{N, m}-T_{N, m}^{2}}{\Delta t}+\frac{\pi d_{N}}{\Delta r N_{\theta}} k_{f}\left(T_{N, m}-T_{N-1, m}\right) \\
& +\frac{\pi d_{f u e l} H_{g}}{N_{\theta}}\left(T_{N, m}-T_{c, m}\right) \\
& +\frac{2 \Delta r N_{\theta}}{\pi\left(d_{\text {fuel }}+d_{N}\right)}\left(2 T_{n, m}-T_{n, m-1}-T_{n, m+1}\right)=q_{f}^{\prime \prime \prime} \pi\left(\frac{d_{\text {fuel }}^{2}-d_{N}^{2}}{4 N_{\theta}}\right)
\end{aligned}
$$

\section{Cladding Node $\mathrm{N}+1$ :}

$$
\begin{aligned}
& \pi\left[\frac{d_{c l a d}^{2}-\left(d_{c l a d}-2 t_{c l a d}\right)^{2}}{4 N_{\theta}}\right] \rho_{c} c_{p_{c}} \frac{T_{c, m}-T_{c, m}^{n}}{\Delta t}+\pi \frac{d_{f v e l} H_{g a p}}{N_{\theta}}\left(T_{c, m}-T_{N, m}\right) \\
& +\frac{\pi d_{c l a d} H_{s u r f}}{N_{\theta}}\left(T_{c, m}-T_{f l u i d, m}\right) \\
& +\frac{\Delta r N_{\theta} k_{c}}{\pi\left(d_{c l a d}-t_{c l s d}\right)}\left(2 T_{c, m}-T_{c, m-1}-T_{c, m+1}\right) \\
& +\sum_{n \in(N+1)}\left(\pi D_{r o d}\right) \sigma F_{N+1, n}\left(T_{c}^{4}-T_{c, n}^{4}\right) \\
& +\sum_{m \in(N+1)}\left(A_{s} / \Delta X_{j}\right) \sigma F_{(N+1), m}\left(T_{c}^{4}-T_{w, m}^{4}\right)=0
\end{aligned}
$$

\subsubsection{Slab Energy Equation}

The heat transfer model for the solid structure nodes is formulated for an arbitrary control volume that can exchange energy with the fluid and with other solid structure nodes by conduction or radiative heat transfer. A solid structure node (called a slab node to differentiate it from a fuel rod node) can also exchange energy with the rods by radiative heat transfer. The axial noding of a slab corresponds to axial noding of the subchannels. The cross-sectional area for axial heat transfer in a slab node is defined by input. A slab control volume may have any number of surfaces connected to adjacent slab nodes or fluid subchannels. These connections and their dimensions are defined by user input. 
In addition to conductive and convective heat transfer between the slab node and adjacent slab or fluid nodes, the control volume can also exchange energy via thermal radiation with the surfaces of fuel rods and other slabs. Given the above assumptions and definitions, the conduction equation for the slab node can be written in finite difference form as

$$
\begin{aligned}
& A_{s} \Delta X_{j} \rho_{w} c_{p_{w}} \frac{T_{w}-T_{w}^{D}}{\Delta t}=-\Delta x_{j} \sum_{i \in m} P_{w} H_{s \text { surf }}\left(T_{\text {wall }}-T_{i}\right) \\
& -\sum_{m \in i} U\left(T_{\text {wall }}-T_{\text {wall }}\right) \\
& +\sum_{m \in i} A_{w} \sigma F_{i m}\left(T_{p r a l l}{ }^{4}-T_{w_{\text {wall }}}{ }^{4}\right)-\sum_{n \in i} A_{T} \sigma F_{n m}\left(T_{\text {wall }^{4}}-T_{\text {clad }_{n}}{ }^{4}\right) \\
& +\left[U_{j}\left(T_{\text {wall }}-T_{\text {wall } j+1}\right)+U_{j-1}\left(T_{\text {wall }}-T_{\text {wall }_{j-1}}\right)\right]
\end{aligned}
$$

As with the rod equation, radiation is assumed to occur only in a given axial plane. Conduction between two slab nodes is modeled using a composite thermal conductance $(U)$ which accounts for the heat transfer area, the thermal conductivity of the slab materials, and any gap resistance or thermal radiation at the slab interface. In the axial direction, composite thermal conductances through the top and the bottom of the slab node are calculated, denoted as $U_{j}$ and $U_{j-1}$, respectively. The actual values used in a given problem are determined from user input of appropriate empirical conduction resistances for the various node connections. 


\subsection{Transient Capability Verification}

Verification and validation testing is an essential part of any software development program. This is especially important for computational fluid dynamics (CFD). codes, since they contain a wide variety of mathematical and physical models. Verification is testing to ensure that the mathematical models are correctly coded into the software. This is accomplished by comparing calculational results to analytical solutions that exist in the literature. These problems are of necessity relatively simple, and are usually much less challenging to a code than the "real world" applications for which it is intended. Therefore, additional validation testing is necessary to show that the mathematical models in the code accurately represent the physics of interest. This is accomplished by comparing calculational results with relevant experimental data.

The validation and verification that was done to support the initial release and licensing of COBRASFS had been based solely on steady-state applications, even though the appropriate transient terms were included in the original equations. Most applications of the code involve primarily steady-state calculations, but the transient capability is useful for a variety of analyses. Storage and transportation casks will not generally be subjected to transients intentionally, but there are possible accidents to consider. The safety evaluation of transportation casks may require including an analysis of various hypothetical events, such as exposure to fire for a specified period of time. Analysis of any conditions, hypothetical or real, in which the stored energy terms can be significant requires the ability to perform a transient analysis for the cask.

Verification of the transient capability in COBRA-SFS is accomplished by comparing code calculations to analytical solutions to the conduction equation with various boundary conditions. These results are presented in Section 3.1 below. In addition, comparisons with analytical flow solutions are presented in Section 3.2. Validation calculations for the transient capability, consisting of comparisons with storage cask experimental data, are presented in Section 4.

\subsection{Transient Heat Transfer Solutions}

COBRA-SFS solves equations for mass, momentum, and energy conservation, but from the standpoint of accurate cask analysis, the energy equations are perhaps the most important. Heat transfer in a cask occurs by means of convection, conduction, and radiative exchange, and the models in the code must properly capture the physical behavior in all three modes. Analytical solutions are readily available only for the first two of these modes, convection and conduction. The cases selected for comparison to COBRA-SFS calculations are conduction in a plate with a step change in boundary temperature, conduction in a plate with uniform internal heat generation, and conduction in a cylinder with a step change in boundary temperature. 
For the cases with conduction in a plate, the geometry is assumed to be a plate of infinite extent in the $y$-direction, and of thickness $2 \mathrm{~L}$ in the $\mathrm{x}$-direction. The plate is at uniform temperature $\mathrm{T}_{0}$, and at time $t=0$ is suddenly plunged into a constant temperature bath at $T_{\infty}$. The temperature in the plate as a function of time and location is given by the conduction equation as

$$
\frac{\partial^{2} T}{\partial x^{2}}=\alpha \frac{\partial T}{\partial t}
$$

The coefficient $\alpha$ is the thermal diffusivity, $\alpha=\mathrm{k} / \mathrm{pc}_{\mathrm{p}}$. Analytical solutions to this partial differential equation are given for different sets of boundary conditions in Sections 3.1.1,3.1.2, and 3.1.3. These are compared with COBRA-SFS calculations using different modeling capabilities of the code.

For cases with conduction in a cylinder, the geometry is assumed to be a cylinder of radius $\mathrm{R}$, having infinite extent in the axial direction. As with the analytical solutions for the plate, the cylinder is at uniform temperature $T_{0}$, and at time $t=0$ is suddenly plunged into a constant temperature bath at $T_{\infty}$. The temperature in the cylinder as a function of time and radial position is given by the conduction equation as

$$
\frac{\partial \mathrm{T}}{\partial \mathrm{t}}=\frac{\alpha}{\mathrm{r}} \frac{\partial}{\partial \mathrm{r}}\left(\mathrm{r} \frac{\partial \mathrm{T}}{\partial \mathrm{r}}\right)
$$

An analytical solution to this partial differential equation is given for a step change in the boundary temperature in Section 3.1.4. The analytical solution is compared with COBRA-SFS calculations using both the slab conduction model and the rod conduction model.

\subsubsection{Conduction in a Plate with Infinite Surface Heat Transfer Coefficient}

A solution for Equation (3.1) can be obtained by separation of variables for the specified boundary conditions of initial uniform temperature $T_{0}$ with a step change at time $t=0$ to boundary temperature $T_{\text {. }}$. (Arpaci 1966). Assuming an infinite heat transfer coefficient at the surface, the temperature profile in the $\mathrm{x}$-direction as a function of time is given by

$$
\frac{T(x, t)-T_{\infty}}{T_{0}-T_{\infty}}=2 \sum_{n=0}^{\infty} \frac{(-1)^{n}}{\lambda_{n} L} e^{-\alpha \lambda_{n}^{2} t} \cos \left(\lambda_{n} x\right)
$$

The eigenvalues $\lambda_{n}$ of the solution given by Equation (3.3) are defined by the relation, 


$$
\lambda_{n} L=(2 n+1) \pi / 2
$$

For the COBRA-SFS calculations, the plate was assigned a thickness of 20 inches, and thermal diffusivity, $\alpha$, of $10 \mathrm{ft}^{2} / \mathrm{hr}$. The initial uniform temperature $T_{0}$ was assumed to be $200^{\circ} \mathrm{F}$. At time $t=0$, the boundary temperature $T_{\infty}$ was changed to $100^{\circ} \mathrm{F}$. Two COBRA-SFS input models were constructed for this problem. In the first case, the plate was modeled as 10 uniform slab nodes representing the width $\mathrm{L}$ from the plate centerline to the boundary. The medium surrounding the plate was modeled as a large channel with a very large surface heat transfer coefficient between the fluid and the surface of the first slab node. The results obtained with this model are compared with the analytical solution in Figures 3.1 and 3.2.

Figure 3.1 shows the temperature profiles at selected time intervals in the transient, obtained in COBRA-SFS using the slab model. The symbols on the plot represent the code results, and the lines (solid, dotted, and variously dashed) represent the analytical solution. As can be seen from the figure, the code results are essentially identical to the analytical solution for this problem. Figure 3.2 shows similar excellent agreement between the code calculations and the analytical results for the centerline temperature of the plate as a function of time.

The results obtained with the slab model show that the conduction equation for the slab nodes is properly implemented in COBRA-SFS. However, the code also considers conduction in the fluid, as part of the fluid energy equation, which is solved separately from the conduction equation in the solid nodes. A second COBRA-SFS model was constructed for this problem, in which the plate was modeled as a row of 10 fluid subchannels, rather than as 10 solid nodes. The results obtained with this model are compared to the analytical solution in Figure 3.3. As with the results obtained with the slab model, the calculated temperature profiles (represented by the symbols on the plot in Figure 3.3) are in excellent agreement with the analytical results.

The results of the comparisons shown in Figures 3.1 through 3.3 show that the energy equation for conduction is properly implemented in the COBRA-SFS code for the slab nodes and for the fluid in the subchannels. 


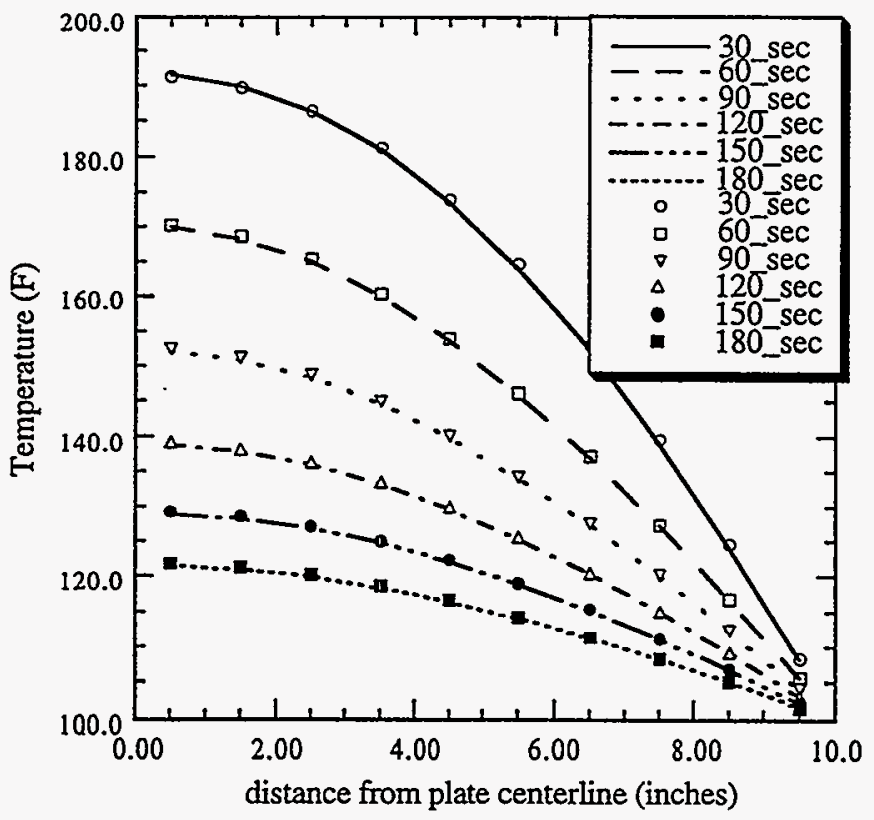

Figure 3.1. Temperature Profiles in a Plate with Infinite Heat Transfer Boundary Condition; COBRA-SFS Calculations with Slab Model

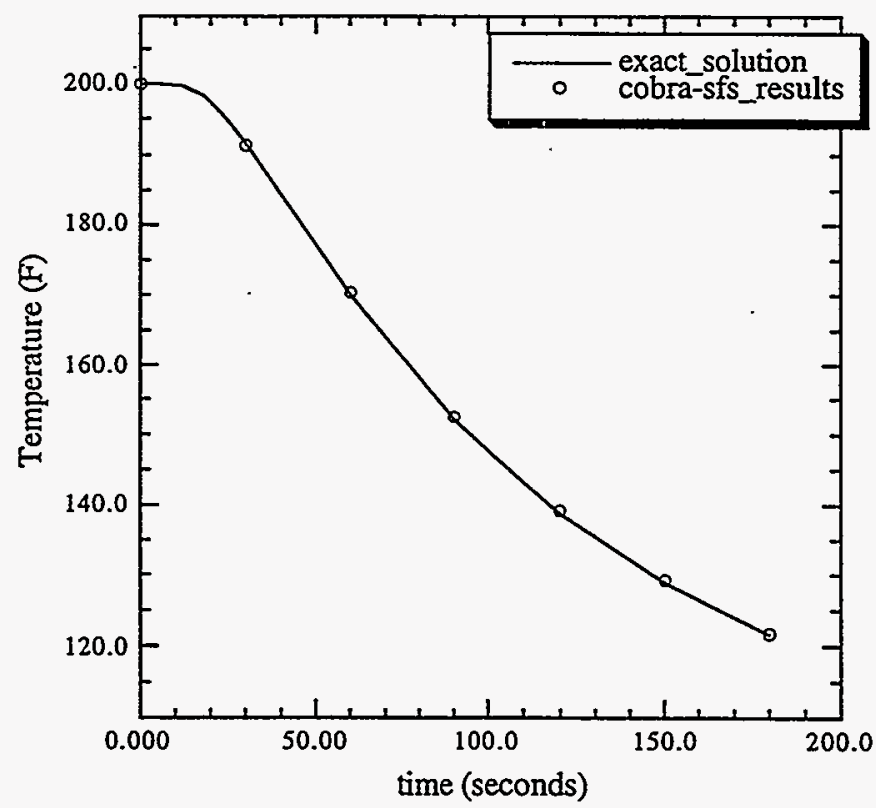

Figure 3.2. Centerline Temperature History Calculated with COBRA-SFS (slab model) 


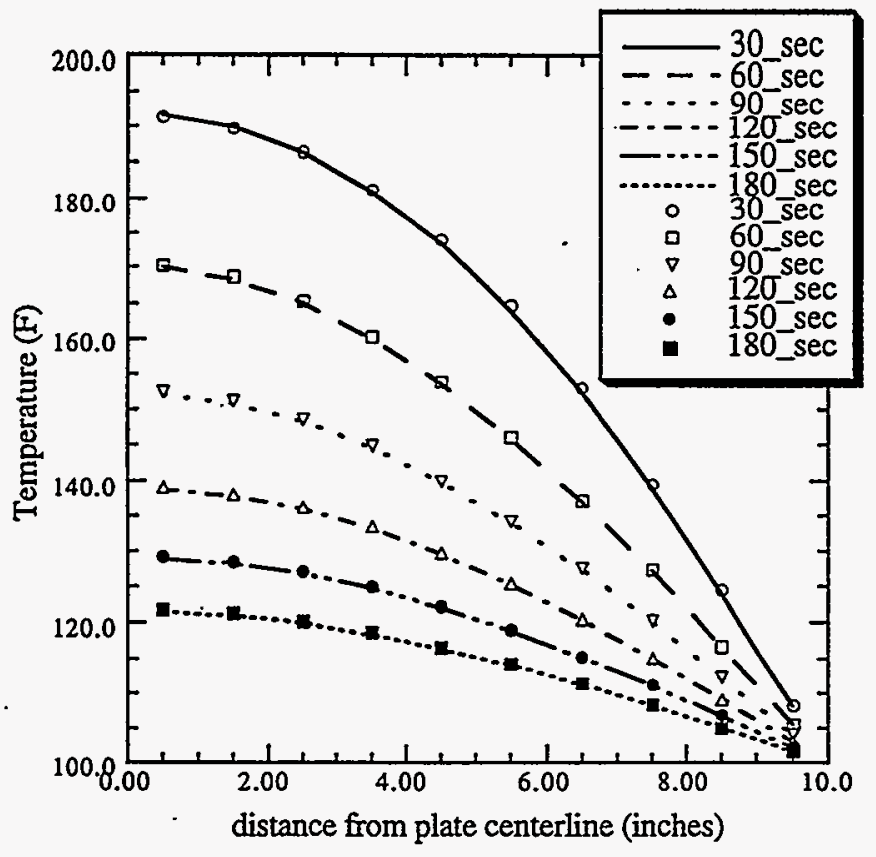

Figure 3.3. Temperature Profiles in a Plate with Infinite Heat Transfer Boundary Condition; COBRA-SFS Calculations with Subchannel Model 


\subsubsection{Conduction in a Plate with Nominal Surface Heat Transfer Coefficient}

A somewhat more realistic solution for Equation (3.1) can be obtained by assuming that the surface heat transfer coefficient is some finite value, rather than effectively infinite (Arpaci 1966). For the same boundary conditions of initial uniform temperature $T_{0}$ with a step change at time $t=0$ to boundary temperature $T_{\infty}$, the temperature profile in the $x$-direction as a function of time is given by

$$
\frac{T(x, t)-T_{\infty}}{T_{0}-T_{\infty}}=2 \sum_{n=0}^{\infty} \frac{\sin \left(\lambda_{n} L\right)}{\lambda_{n} L+\sin \left(\lambda_{n} L\right) \cos (\lambda N L)} e^{-\alpha \lambda_{n}{ }^{2} t} \cos \left(\lambda_{n} x\right)
$$

The eigenvalues of the solution given by Equation (3.4) are defined by the relation

$$
\left(\lambda_{n} L\right) \sin \left(\lambda_{n} L\right)=B i \cos \left(\lambda_{n} L\right)
$$

The heat transfer coefficient is specified by means of the Biot number, $\mathrm{Bi}$, as

$$
\mathrm{Bi}=\frac{\mathrm{hL}}{\mathrm{k}}
$$

For the COBRA-SFS calculations, the same geometry was used for this case as for the case with infinite heat transfer coefficient. That is, the plate was assigned a thickness of 20 inches, and thermal diffusivity, $\alpha$, of $10 \mathrm{ft}^{2} / \mathrm{hr}$. The initial uniform temperature $T_{0}$ was assumed to be $200^{\circ} \mathrm{F}$. At time $t=0$, the boundary temperature $T_{\infty}$ was changed to $100^{\circ} \mathrm{F}$. The plate was modeled as 10 uniform slab nodes representing the width $\mathrm{L}$, from the plate centerline to the boundary. The medium surrounding the plate was modeled as a large channel, and the surface heat transfer coefficient was specified at $1.2 \mathrm{Btu} / \mathrm{hr}-\mathrm{ft}^{2}$ to produce a Biot number of 1.0 the same value as that used in the exact solution.

Figure 3.4 shows the temperature profiles at selected time intervals in the transient obtained in COBRA-SFS using the slab model. The symbols on the plot represent the code results, and the lines (solid, dotted, and variously dashed) represent the analytical solution. As can be seen from the figure, the code results are essentially identical to the analytical solution for this problem. The results of this case show that the conduction equation for the slab nodes and convective heat transfer terms in the fluid energy equation are properly represented in the code. 


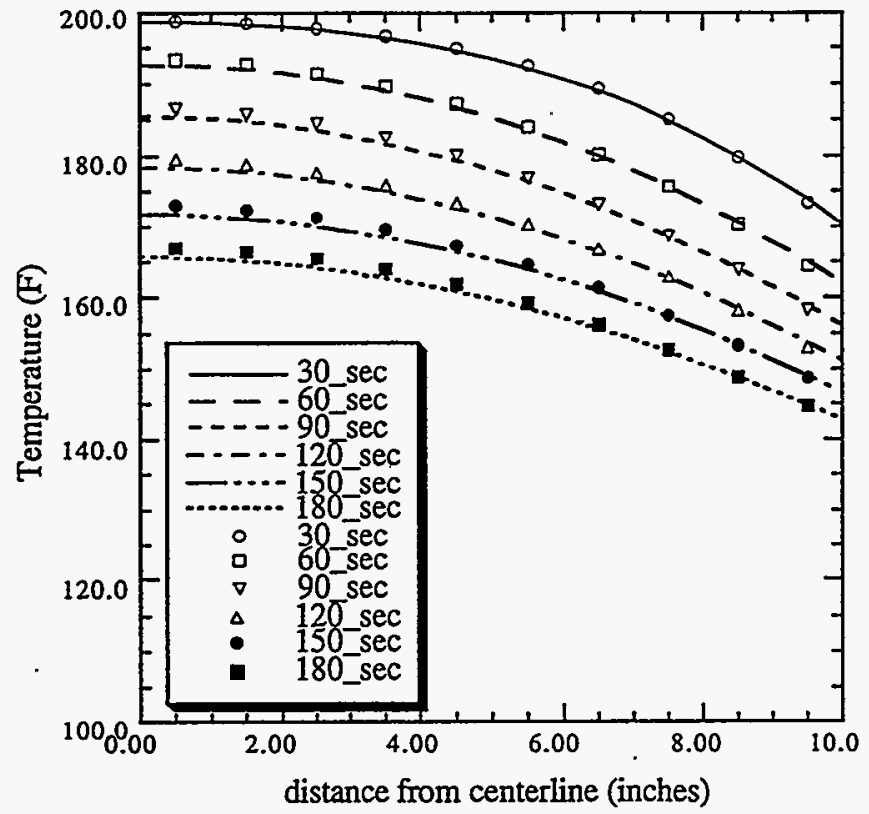

Figure 3.4. Temperature Profiles in a Plate with Nominal Heat Transfer Boundary Condition; COBRA-SFS Calculations with Slab Model 


\subsubsection{Conduction in a Plate with Uniform Internal Heat Generation}

This verification case is similar to the two cases described in Sections 3.1.1 and 3.1.2, except that the basic conduction equation must include the heat generation term, denoted $\mathrm{u}^{\prime \prime}$. The boundary temperature for this case remains constant at $100^{\circ} \mathrm{F}$, but at time $t=0$, the heat generation term changes from zero to a constant positive value. The conduction equation for this case is given by

$$
\frac{\partial T}{\partial t}=\alpha \frac{\partial^{2} T}{\partial x^{2}}+\frac{u^{\prime \prime \prime}}{\rho c_{p}}
$$

The solution to this equation (Arpaci 1966) gives the temperature profile in the plate in the $\mathrm{x}$-direction as a function of time

$$
\frac{\left(T(x, t)-T_{\infty}\right)}{u^{\prime \prime \prime} L^{2} / k}=\frac{1}{2}\left[1-\left(\frac{x}{L}\right)^{2}\right]-2 \sum_{n=0}^{\infty} \frac{(-1)^{n}}{\left(\lambda_{n} L\right)^{3}} e^{-\alpha \lambda_{n}{ }^{2} t} \cos \left(\lambda_{n} x\right)
$$

The eigenvalues of the solution given by Equation (3.6) are defined by the relation

$$
\lambda_{\mathrm{n}} \mathrm{L}=(2 \mathrm{n}+1) \pi / 2
$$

For the COBRA-SFS calculations, the same geometry was used for this case as for the cases in Sections 3.1.1 and 3.1.2. That is, the plate was assigned a thickness of 20 inches, and thermal diffusivity, $\alpha$, of $10 \mathrm{ft}^{2} / \mathrm{hr}$. The initial uniform temperature $T_{0}$ was assumed to be $100^{\circ} \mathrm{F}$. At time $t=0$, the heat generation rate in the slab nodes was specified as $100 \mathrm{Btu} / \mathrm{hr}_{\mathrm{ft}} \mathrm{ft}^{3}$. The plate was modeled as 10 uniform slab nodes representing the width $L$, from the plate centerline to the boundary. The medium surrounding the plate was modeled as a large channel, and the surface heat transfer coefficient was specified as an essentially infinite value.

Figure 3.5 shows the temperature profiles at selected time intervals in the transient, for the analytical solution and those obtained in COBRA-SFS using the slab model. The symbols on the plot represent the code results, and the lines (solid, dotted, and variously dashed) represent the analytical solution. As can be seen from the figure, the code results are essentially identical to the analytical solution for this problem. 


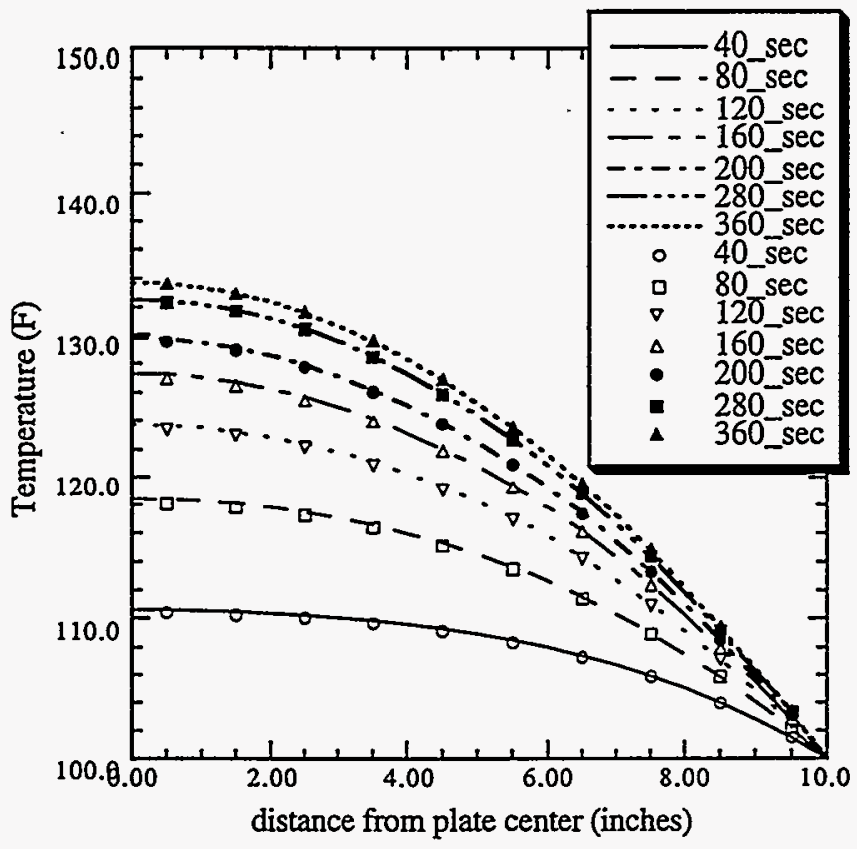

Figure 3.5. Temperature Profiles in a Plate with Uniform Heat Generation Rate; COBRA-SFS Calculations with Slab Model 


\subsubsection{Conduction in a Cylinder}

The analytical solution for the case with conduction in a cylinder is similar to those for the conduction in a plate. A solution for Equation (3.2) can also be obtained by separation of variables for the specified boundary conditions of initial uniform temperature $T_{0}$ with a step change at time $t=0$ to boundary temperature T. (Arpaci 1966). Assuming an infinite heat transfer coefficient at the surface, the temperature profile in the $\mathrm{x}$-direction as a function of time is given by

$$
\frac{T(r, t)-T_{\infty}}{T_{0}-T_{\infty}}=2 \sum_{n=}^{\infty} \frac{e^{-\alpha \lambda_{n}^{2} t} J_{0}\left(\lambda_{n} r\right)}{\left(\lambda_{n} R\right) J_{1}\left(\lambda_{n} r\right)}
$$

The eigenvalues of the solution are defined by

$$
J_{0}\left(\lambda_{n} r\right)=0
$$

For the COBRA-SFS calculations, the cylinder was assumed to be one inch in diameter, with a thermal diffusivity, $\alpha$, of $0.01 \mathrm{ft}^{2} / \mathrm{hr}$. The initial uniform temperature $\mathrm{T}_{0}$ was assumed to be $200^{\circ} \mathrm{F}$. At time $t=0$, the boundary temperature $T_{\infty}$ was changed to $100^{\circ} \mathrm{F}$. Two COBRA-SFS input models were constructed for this problem. In the first case, the cylinder was represented using 10 slab nodes, arranged in concentric rings. In the second case, the cylinder was represented as a fuel rod with 10 internal nodes and a zero-thickness cladding.

In both cases, the COBRA-SFS calculations are in excellent agreement with the analytical solution. Figure 3.6 shows the temperature profiles at selected time intervals in the transient, obtained in COBRASFS using the slab model. Figure 3.7 shows the temperature profiles at the same time intervals obtained using the fuel rod model. The symbols on the plot represent the code results, and the lines (solid, dotted, and variously dashed) represent the analytical solution. As can be seen from the figures, the code results are essentially identical to the analytical solution for this problem. These results show that the energy equation for the slab nodes and that for the rod nodes both give a very good approximation of the conduction equation.

An additional calculation was performed for the rod model, using a nominal heat transfer coefficient of $24.0 \mathrm{Btu} / \mathrm{hr}-\mathrm{ft}^{2}-{ }^{\circ} \mathrm{F}$ boundary condition on the rod surface. The results of this calculation are shown in Figure 3.8, along with the analytical solution. As can be seen from the plot, the code calculations are in excellent agreement with the exact solution, indicating that the terms for conduction and convection heat transfer are properly incorporated in the energy equations in COBRA-SFS. 


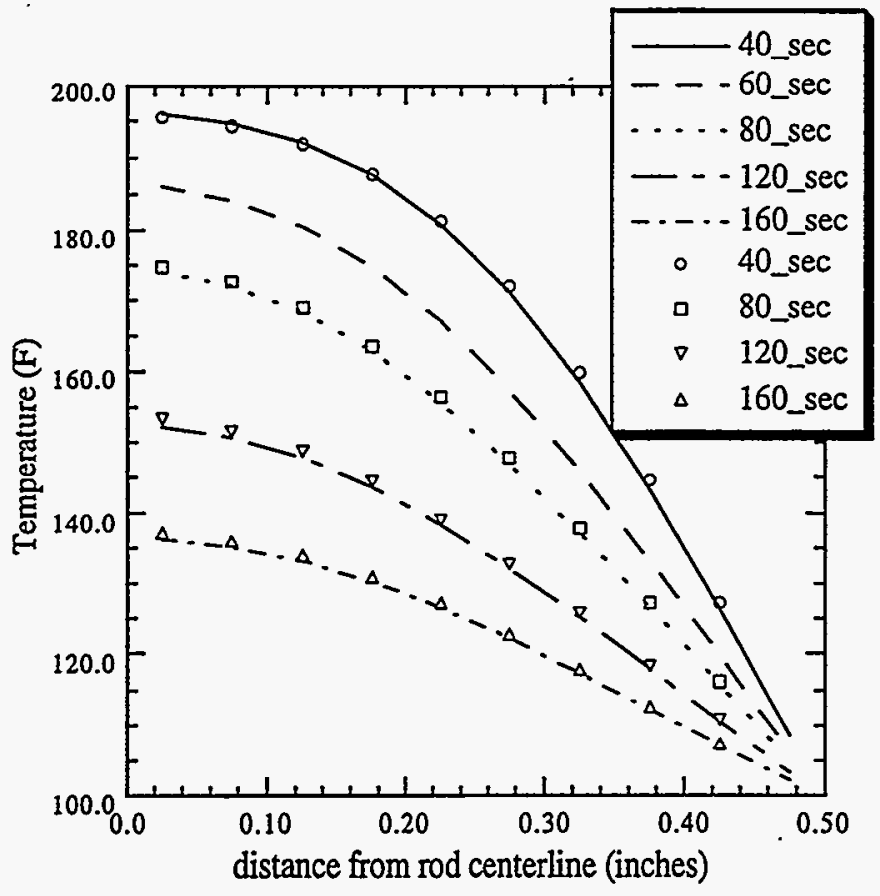

Figure 3.6. Temperature Profiles in a Cylinder with Infinite Heat Transfer Boundary Condition; COBRA-SFS Calculations with Slab Model

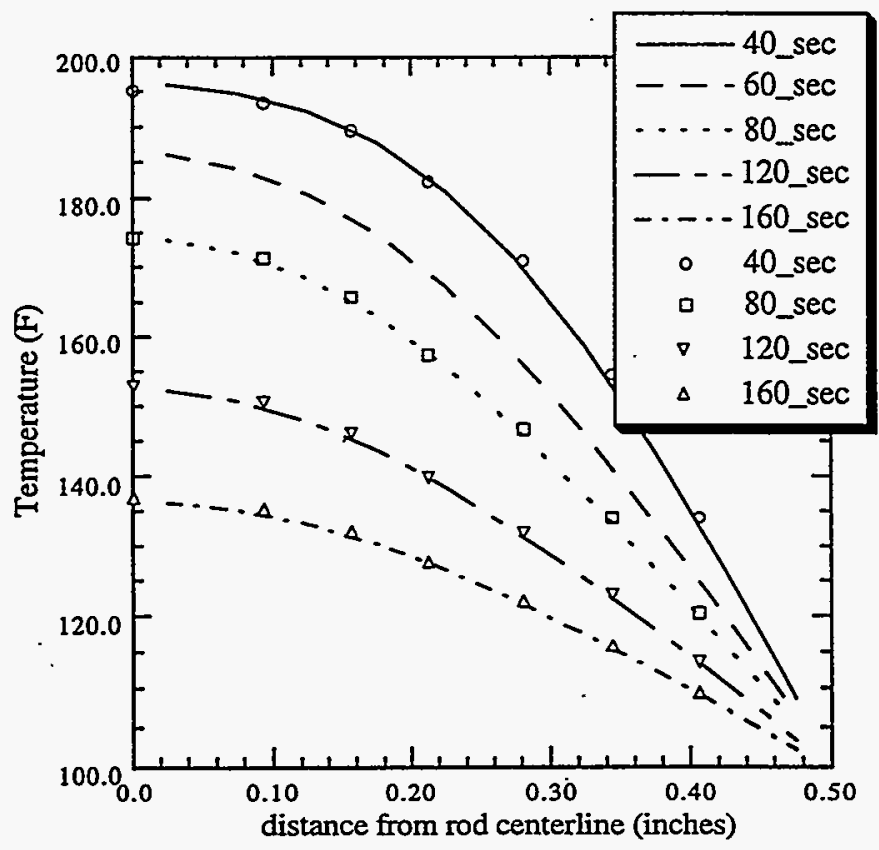

Figure 3.7. Temperature Profiles in a Cylinder with Infinite Heat Transfer Boundary Condition; COBRA-SFS Calculations with Rod Model 


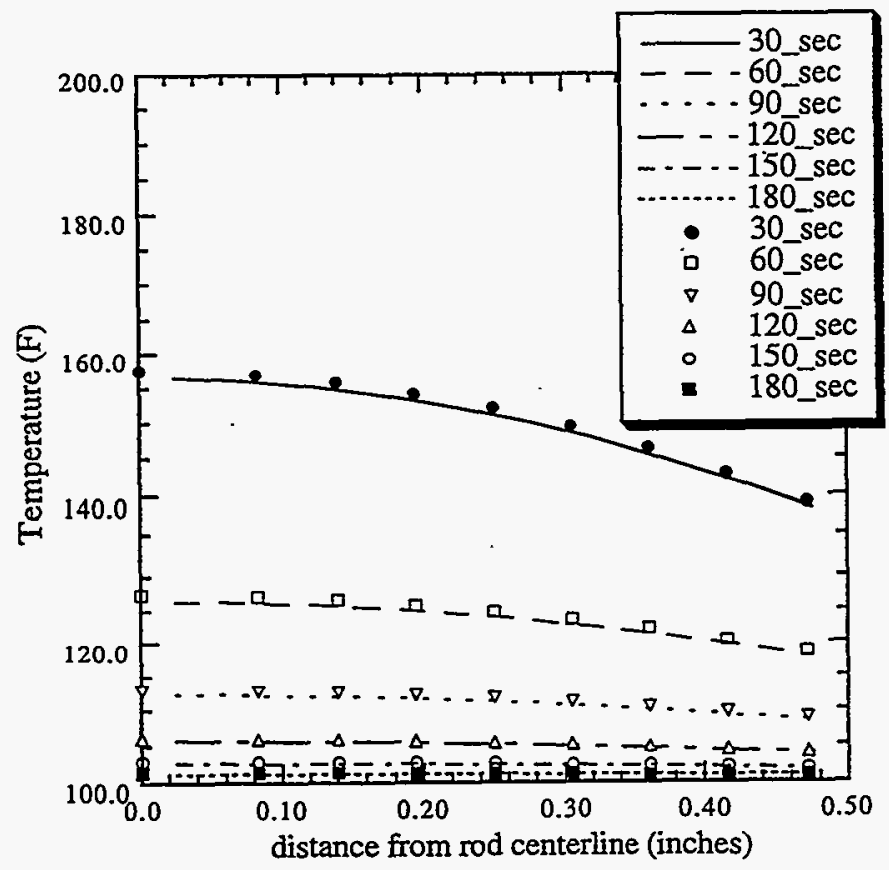

Figure 3.8. Temperature Profiles in a Cylinder with Nominal Heat Transfer Boundary Condition; COBRA-SFS Calculations with Rod Model 


\subsection{Transient Flow Solutions}

Analytical solutions for transient flow conditions are available only for very simple problems. The cases selected for verification of the implementation of the momentum equation in COBRA-SFS are for a flow channel undergoing a step change in the pressure gradient. In the first case, which is described in Section 3.2.1, the flow field is an idealized two-dimensional flow between two parallel plates. In the second case, described in Section 3.2.2, the flow is in a pipe of circular cross-section. In both cases, the flow field is initially steady, with a constant pressure drop and flow. At time $t=0$, a step change in the pressure gradient is imposed. The exact solution describes the evolution of the velocity profile over time in response to the new pressure gradient.

In COBRA-SFS, the effects of wall shear on the fluid velocity can be modeled directly, by specifying zero slip at the wall as a boundary condition, or it can be modeled indirectly, by means of an empirical friction factor correlation. Both modeling approaches are used in the code calculations for comparison to the analytical solutions of the two validation cases presented below.

\subsubsection{Transient Flow Between Two Parallel Plates}

In this case, the flow field initially consists of steady laminar flow between two parallel plates, spaced a distance $2 \mathrm{~h}$ apart. For convenience, the coordinates are defined so that the $\mathrm{x}$-direction is the direction of flow, and the $y$-direction is perpendicular to the direction of flow, with the origin midway between the two plates. For this system, the pressure gradient can be expressed as

$$
K=-\frac{1}{\rho} \frac{d P}{d x}
$$

The momentum equation for this geometry is simply

$$
\frac{d P}{d x}=\mu \frac{d^{2} u}{d y^{2}}
$$

An analytical solution for the velocity profile as a function of time can be obtained by separation of variables (Moore 1964), in the form

$$
u(y, t)=u_{s}(y)-U_{t}(y, t)
$$

The steady-state velocity profile, $u_{s}(y)$, is given by the expression 


$$
u_{s}(y)=\frac{K}{2 v}\left(h^{2}-y^{2}\right)
$$

In these equations, $\rho$ is the fluid density, $\mu$ is the dynamic viscosity, and $v$ is the kinematic viscosity, in consistent units.

The transient component of the velocity in Equation (3.9) is given by

$$
u_{t}(y, t)=\sum_{n=1}^{\infty} a_{n} e^{-\pi^{2}\left(n-\frac{1}{2}\right)^{2} \frac{v t}{h^{2}}} \cos \left(\pi\left(n-\frac{1}{2}\right) \frac{y}{h}\right)
$$

The eigenvalues of the solution are given by

$$
a_{n}=\frac{K h^{2}}{2 v} \frac{4(-1)^{n}}{\pi^{3}\left(n-\frac{1}{2}\right)^{3}}
$$

For the COBRA-SFS calculations, the flow channel was specified with a total width of 20 inches, and was assumed to be $10 \mathrm{ft}$. long. Taking advantage of axial symmetry, the model for the code represented one half of the width of the channel with 20 subchannels, each 0.5 -inch wide. The plate forming the wall of the channel was modeled with a single slab. The properties of the fluid were specified with density $62.4 \mathrm{lbm} / \mathrm{ft}^{3}$ and kinematic viscosity $10^{-5} \mathrm{ft}^{2} / \mathrm{sec}$. The laminar zero-slip boundary condition was specified for the subchannel in contact with the slab node modeling the plate. The option for fluid-fluid shear between adjacent subchannels was specified as active for the calculations in the code.

The results obtained with COBRA-SFS for this case are shown in Figure 3.9, with velocity profiles at four different times in the course of the transient. The symbols on the plot represent the code results, and the lines (solid, dotted, and variously dashed) represent the analytical solution. As can be seen from the figure, the code calculations are in excellent agreement with the analytical solution at all times during the transient, and for the initial steady state profile at time zero. 


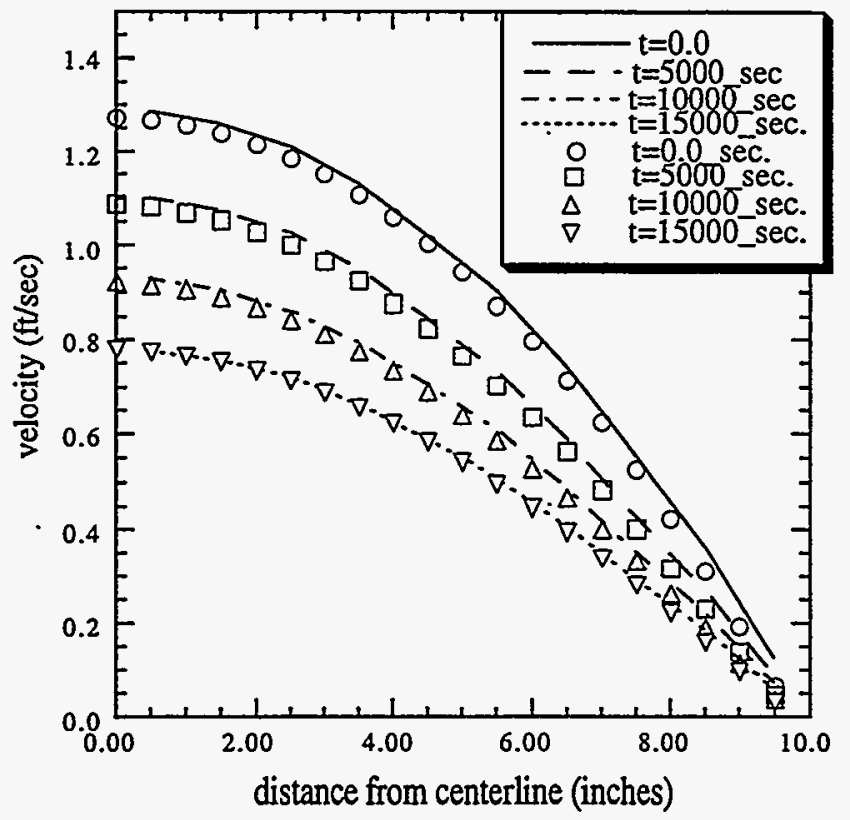

Figure 3.9. Velocity Profiles for Flow Between Two Parallel Plates; COBRA-SFS Calculations with Zero-Slip at the Wall Boundary Condition 


\subsubsection{Transient Flow in a Pipe}

In this case, the flow field is initially stagnant, with zero flow and a pressure gradient of zero. The geometry is a cylindrical pipe with diameter $\mathrm{D}$. At time $\mathrm{t}=0$, a constant pressure drop of $0.001 \mathrm{psi}$ is imposed on the pipe. An analytical solution (Szymanski 1932) for the average axial velocity in the pipe can be obtained from the expression

$$
\frac{\bar{u}_{z}}{\left(\bar{u}_{z}\right)_{\infty}}=1-\left(0.963 \mathrm{e}^{-0.36 \theta \mathrm{f}_{-}}+0.036 \mathrm{e}^{-1.90 \Theta \mathrm{f}_{-}}+\ldots\right)
$$

The complete solution contains an infinite series of exponential terms, but only the first two are needed for an adequate representation of the profile. The dimensionless time $\Theta$ in Equation (3.11) is defined as

$$
\Theta=t \frac{\left(\bar{u}_{z}\right)_{\infty}}{D}
$$

The pipe was assumed to have an inside diameter of 1 inch and overall length of $10 \mathrm{ft}$. for the COBRA-SFS calculations. The fluid was assumed to have density $62.4 \mathrm{lbm} / \mathrm{ft}^{3}$ and kinematic viscosity . $10^{-5} \mathrm{ft}^{2} / \mathrm{sec}$. Two different models were used in COBRA-SFS to represent the flow field in the pipe.

In the first case, the laminar zero-slip boundary condition was specified for the subchannel in contact with the slab node modeling the wall of the pipe. The flow field within the pipe was modeled with 10 concentric channels consisting of annular rings of equal thickness. The option for fluid-fluid shear between adjacent subchannels was specified as active for the calculations in the code.

In the second case, the flow field within the pipe was modeled with a single channel, and the wall shear was modeled using the empirical friction factor for laminar flow,

$$
f_{\infty}=\frac{64.0}{R e_{D}}
$$

In the COBRA-SFS calculations for both models, the initial pressure drop was specified as zero. Then after time zero, the pressure drop was increased in one time step to $0.001 \mathrm{psi}$. The results obtained with the code are compared to the exact solution in Figure 3.10.

As can be seen from the figure, the COBRA-SFS calculations for the detailed subchannel model with fluid-fluid shear and zero slip at the wall give essentially the same results as the analytical solution. 
In addition, the results for the lumped channel model using the empirical friction factor correlation do not follow the evolution of the average velocity exactly, but the calculation comes to essentially the same result in steady state. This is expectable, since the empirical friction factor correlation is based on steady-state flow behavior, and not transient conditions. The largest difference in the average velocity between the 1-channel model results and the exact solution is only $0.061 \mathrm{ft} / \mathrm{sec}$, however, and these calculational results follow very nearly the same transient curve as the exact solution and come to the same steady state solution. These results show that the zero slip at the wall boundary condition in the COBRA-SFS code properly represents the physics of momentum transfer in the fluid, and the empirical model can also give a reasonable approximation of this behavior, even for transient flow conditions. 


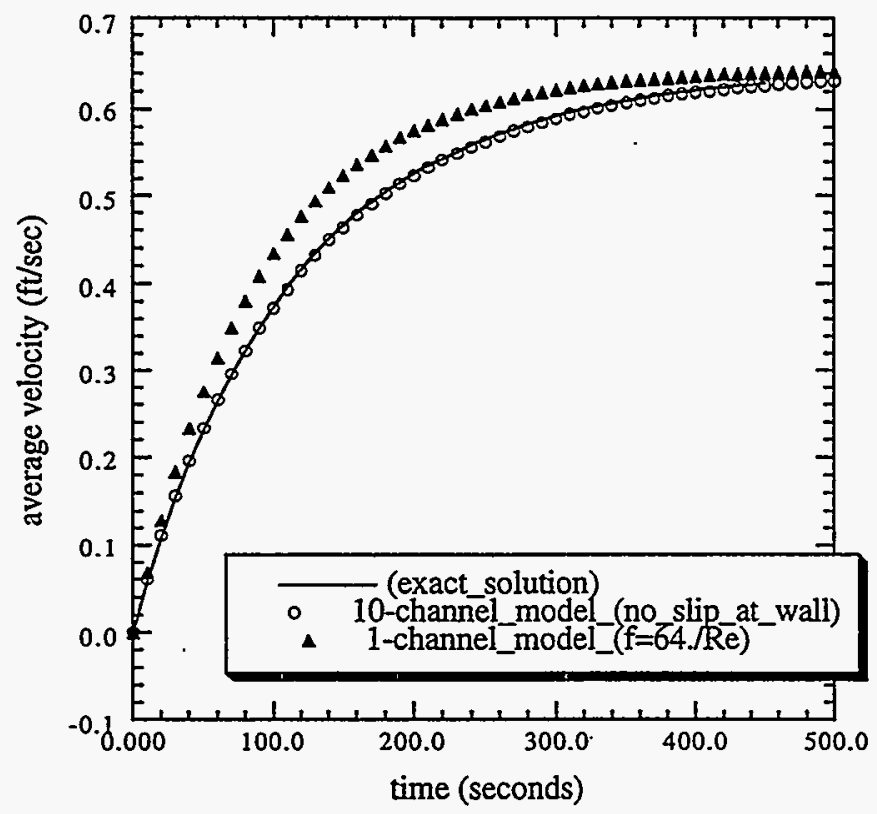

Figure 3.10. Average Velocity Evolution for Transient Flow in a Pipe; COBRA-SFS Calculations for Zero-Slip at the Wall Boundary Condition and for Subchannel Model with Empirical Friction Factor 


\subsection{Transient Capability Validation}

As noted in Section 3.0, the validation for COBRA-SFS, Cycle 2 consisted of comparisons of code calculations with steady state experimental data only. These comparisons included data from three single-assembly experiments ${ }^{(a)}$ and test results for two multiple-assembly storage casks. COBRA-SFS calculations have been compared with data obtained in a large number of different storage and shipping cask designs. The two cask designs included in the Cycle 2 validation were the TN24P cask with intact fuel and the PSN concrete cask with consolidated fuel. For the Cycle 2 validation, only conditions that could be considered as steady state were selected from the experimental data obtained in test programs with the storage casks. These test programs, however, were in fact long term experiments that included a number of transients, as test conditions were changed to evaluate the effects of fill media, cask orientation, and external boundary conditions on peak temperatures.

These transients included changing the fill gas from helium to nitrogen, from nitrogen to vacuum, from vacuum to helium. For the TN24P cask, the orientation was changed from vertical to horizontal approximately a third of the way through the test program. In the PSN cask, cooling vents were opened, closed, and partially blocked at different times during the program, and with the different fill gases in place. These changes in test conditions generally resulted in a relatively rapid change in cask internal temperatures, which could be modeled in COBRA-SFS as a transient between the essentially steady state conditions that obtained before and after the change. Section 4.1 presents the results of the transient calculations for the TN24P cask temperatures, and Section 4.2 gives the results obtained for comparison to the PSN cask data.

\subsection{TN24P ${ }^{(b)}$ Cask Transient}

The TN24P spent fuel storage cask was designed to hold up to 24 spent fuel assemblies and dissipate heat loads of up to $24 \mathrm{~kW}$. A cut-away diagram of the cask is shown in Figure 4.1. The cask body is of forged steel surrounded by a resin layer for neutron shielding and has a steel outer shell. The overall

(a) Electrically heated bundles modeling intact PWR fuel in a square canister; refer to the Cycle 2 release document (Michener et al. 1995, specifically, Part III-Programmer's Manual), for complete documentation and references for these tests and other COBRA-SFS validation calculations.

(b) The TN24P spent fuel storage cask was constructed by Transnuclear, Inc. under a cooperative program between Virginia Power and the U.S. Department of Energy. Testing was conducted jointly by Virginia Power, the Pacific Northwest Laboratory (currently named the Pacific Northwest National Laboratory, operated for DOE by Battelle), and the Idaho National Engineering Laboratory (at the time of this work, INEL was operated for DOE by EG\&G, Inc.; it is currently named the Idaho Engineering Environmental Laboratory, operated by Lockheed-Martin). The Electric Power Research Institute also participated, through a separate agreement with Virginia Power. The program is fully documented elsewhere (McKinnon et al. 1989). 
cask length is $16 \mathrm{ft}(5.0 \mathrm{~m})$, with an outer diameter of $7.5 \mathrm{ft}(2.3 \mathrm{~m})$. When loaded with unconsolidated spent fuel, it weighs approximately 100 tons.

Figure 4.2 shows a cross-section through the center of the cask. The spent fuel basket consists of stacked interlocking plates of aluminum and boron. For the 'hot' tests, the cask was loaded with spent fuel from the Surry nuclear plant. This fuel was standard Westinghouse $15 \times 15$ PWR fuel with nominal rod diameter of $0.420 \mathrm{in} .(1.067 \mathrm{~cm})$ in a square array with $0.563 \mathrm{in.}(1.430 \mathrm{~cm})$ pitch. Nominal fuel column length was $144 \mathrm{in}$. $(365.8 \mathrm{~cm})$, and fuel burnup was approximately $30 \mathrm{GWd} / \mathrm{MTU}$ for each assembly.

Decay heat rates in the fuel rods for the duration of the tests were calculated using ORIGEN2 (Croff 1980). The average power per assembly was approximately $850 \mathrm{~kW}$, and the predicted power at the start of testing was $20.6 \mathrm{~kW}$. At the end of testing, the predicted power was $20.3 \mathrm{~kW}$, which is close enough to the initial power to justify the assumption of a constant power generation rate used in the COBRASFS calculations. Six tests were performed to assess the thermal response of the TN24P cask; three with the cask oriented vertically and three with the cask horizontal. In each orientation, tests were run with three different back-fills; helium, air, and vacuum (i.e., air at approx. 0.5 mbar). Table 4.1 contains a summary of the test matrix.

Table 4.1. TN24P Cask Test Matrix

\begin{tabular}{|c|c|c|c|c|c|}
\hline $\begin{array}{c}\text { Run } \\
\text { Number }\end{array}$ & $\begin{array}{c}\text { Approximate } \\
\text { Start Time of } \\
\text { Transient }\end{array}$ & $\begin{array}{l}\text { Approximate } \\
\text { Time New } \\
\text { Steady State } \\
\text { Obtained }\end{array}$ & $\begin{array}{c}\text { Approximate } \\
\text { Duration of } \\
\text { Transient }\end{array}$ & $\begin{array}{l}\text { Net Change in } \\
\text { Estimated Peak } \\
\text { Clad Temperature }\end{array}$ & Description of Transient \\
\hline 1 & $\begin{array}{l}\text { Initial cask } \\
\text { loading }\end{array}$ & $\begin{array}{l}1 / 12 / 89 \\
12: 00: 00\end{array}$ & & & $\begin{array}{l}\text { Program start-up; cask } \\
\text { vertical with helium backfill }\end{array}$ \\
\hline 2 & $\begin{array}{l}1 / 14 / 86 \\
06: 00: 00\end{array}$ & $\begin{array}{l}1 / 14 / 86 \\
16: 00: 00\end{array}$ & 10 hours & $20^{\circ} \mathrm{C}$ & $\begin{array}{l}\text { Replace helium backfill with } \\
\text { air; cask vertical }\end{array}$ \\
\hline 3 & $\begin{array}{l}1 / 17 / 86 \\
13: 00: 02\end{array}$ & $\begin{array}{l}1 / 19 / 86 \\
12: 00: 02\end{array}$ & 47 hours & $49^{\circ} \mathrm{C}$ & $\begin{array}{l}\text { Air backfill reduced to } \\
\text { vacuum (approx. } 0.5 \text { mbar); } \\
\text { cask vertical }\end{array}$ \\
\hline 4 & $\begin{array}{l}1 / 21 / 86 \\
12: 00: 02\end{array}$ & $\begin{array}{l}1 / 24 / 86 \\
20: 00: 02\end{array}$ & 80 hours & $-75^{\circ} \mathrm{C}$ & $\begin{array}{l}\text { Air at approx. } 0.5 \mathrm{mbar} \\
\text { replaced with helium } \\
\text { backfill at approx. } 1.5 \mathrm{bar} \text {; } \\
\text { cask orientation changed } \\
\text { from vertical to horizontal }\end{array}$ \\
\hline 5 & $\begin{array}{l}1 / 27 / 86 \\
15: 00: 02\end{array}$ & $\begin{array}{l}1 / 28 / 86 \\
14: 00: 02\end{array}$ & 23 hours & $41^{\circ} \mathrm{C}$ & $\begin{array}{l}\text { Replace helium backfill with } \\
\text { air; cask horizontal }\end{array}$ \\
\hline 6 & $\begin{array}{l}2 / 03 / 86 \\
13: 00: 02\end{array}$ & $\begin{array}{l}2 / 04 / 86 \\
14: 00: 02\end{array}$ & 25 hours & $24^{\circ} \mathrm{C}$ & $\begin{array}{l}\text { Air backfill reduced to } \\
\text { vacuum (approx. } 0.5 \text { mbar); } \\
\text { cask horizontal }\end{array}$ \\
\hline
\end{tabular}


Steady-state COBRA-SFS calculations were performed for all six cask configurations, and are documented elsewhere (Creer et al. 1987). For the validation of the transient capability in COBRA-SFS, the transient associated with Run \#5 was selected for comparison with code calculations. The transients in this test program were very similar for each run, consisting mainly of pumping new backfill gases in and out of the system, and any one of the tests could be simulated in the code as a transient. Run \#5 was selected because there is a relatively large change in peak clad temperature over a relatively short time interval ( $+41^{\circ} \mathrm{C}$ over 23 hours), and the time histories of the various instrumentation thermocouples show a reasonably constant steady state before and after the transient.

The results of the COBRA-SFS calculations for this transient are compared to the experimental data in Figure 4.3. The experimental data included in the plot consists of temperature traces from the thermocouple lance in the hot assembly of the cask (identified as D1-5). The uncertainty in the thermocouple measurements has been estimated as $\pm 4^{\circ} \mathrm{C}$. As can be seen from the plot, the temperatures calculated in COBRA-SFS at this location are well within the measurement uncertainty from first to last during the transient, and follow very precisely the shape of the transient temperature curves.

These results were obtained using the COBRA-SFS input files originally developed for the steadystate analyses of Runs 1 through 6 of the TN24P test program. Only one change was made to the input files; for radiative heat transfer, the emissivity of the basket supporting the fuel assemblies was changed from 0.8 to 0.6 . The effect of this change is to reduce slightly the rate at which heat could be removed from the rods by means of radiative heat transfer between the rods and the walls of the enclosing basket supporting the assembly. In the initial steady state, this change in wall emissivity from 0.8 to 0.6 results in an increase of $4.5^{\circ} \mathrm{C}$ in the calculated temperature at the location corresponding to thermocouple lance $\mathrm{D} 1-5$ at $Z=2.317 \mathrm{~m}$. The calculated temperature at this location changes from $215.1^{\circ} \mathrm{C}$ to $219.6^{\circ} \mathrm{C}$. The measured temperature at this location is $214.3^{\circ} \mathrm{C}$, which indicates that the initial steady state gives a slightly conservative estimate of the conditions. Similarly, for the location corresponding to $Z=3.117 \mathrm{~m}$ on D1-5, changing the wall emissivity from 0.8 to 0.6 results in an increase of $4.1^{\circ} \mathrm{C}$ in the calculated temperature, from $199.7^{\circ} \mathrm{C}$ to $203.8^{\circ} \mathrm{C}$. The measured temperature at this location is $200.3^{\circ} \mathrm{C}$.

Given the overall measurement uncertainty, the uncertainties in the boundary conditions, heat transfer modeling uncertainties, and the approximations required by the geometry model selected for this large cask, the calculated initial steady state constitutes a very reasonable estimate of the beginning state for the transient. The fact that the calculational results so faithfully follow the temperature history of the data trace indicates that the COBRA-SFS code correctly accounts for the transient terms in the solution of the energy equation, for both the solid material nodes and the fluid nodes. 


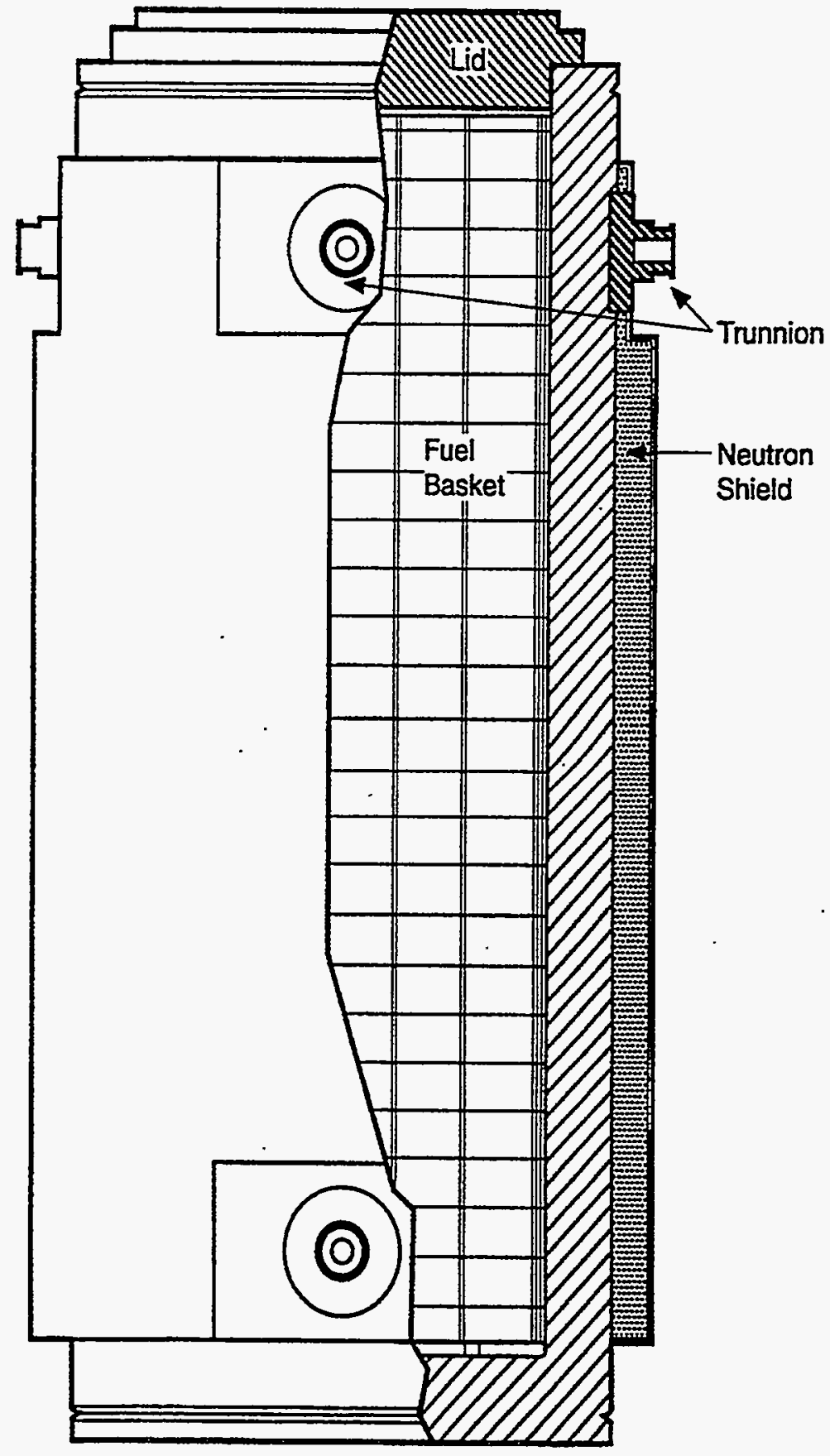

Figure 4.1. TN24P PWR Spent Fuel Storage Cask 


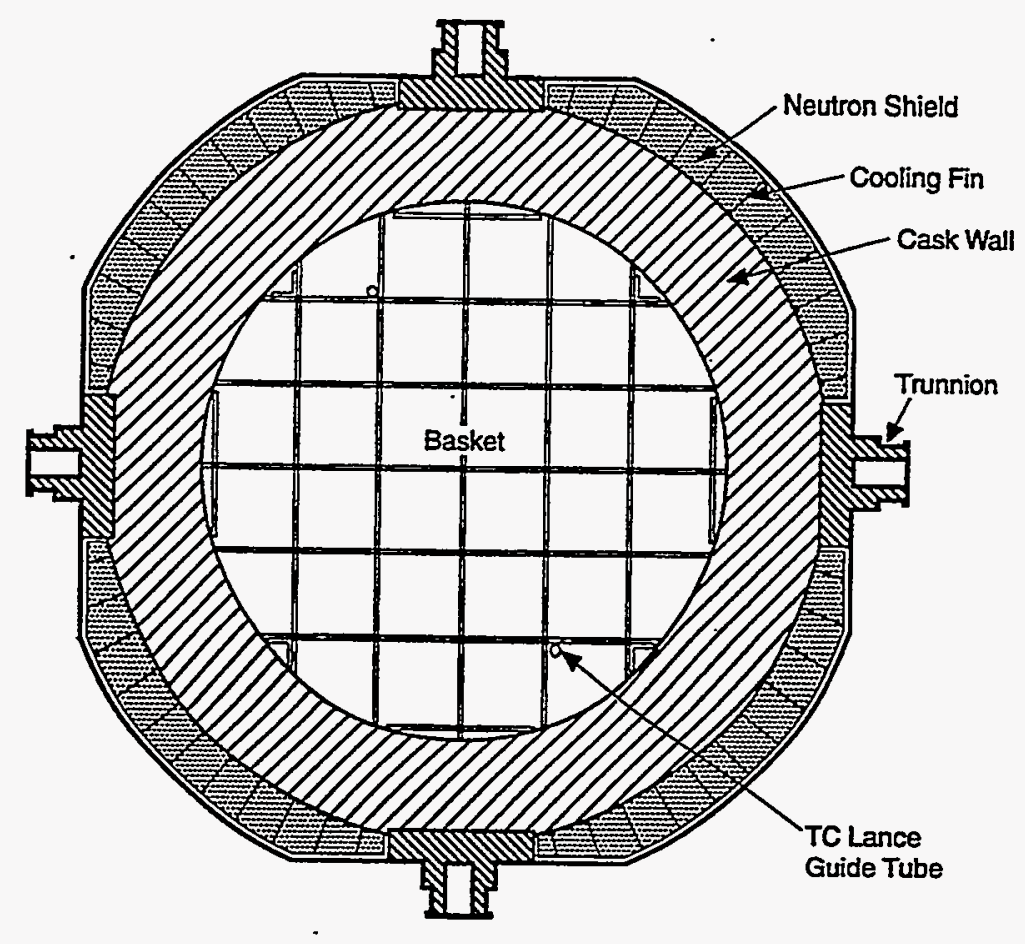

Figure 4.2. TN24P PWR Spent Fuel Storage Cask Cross-Section

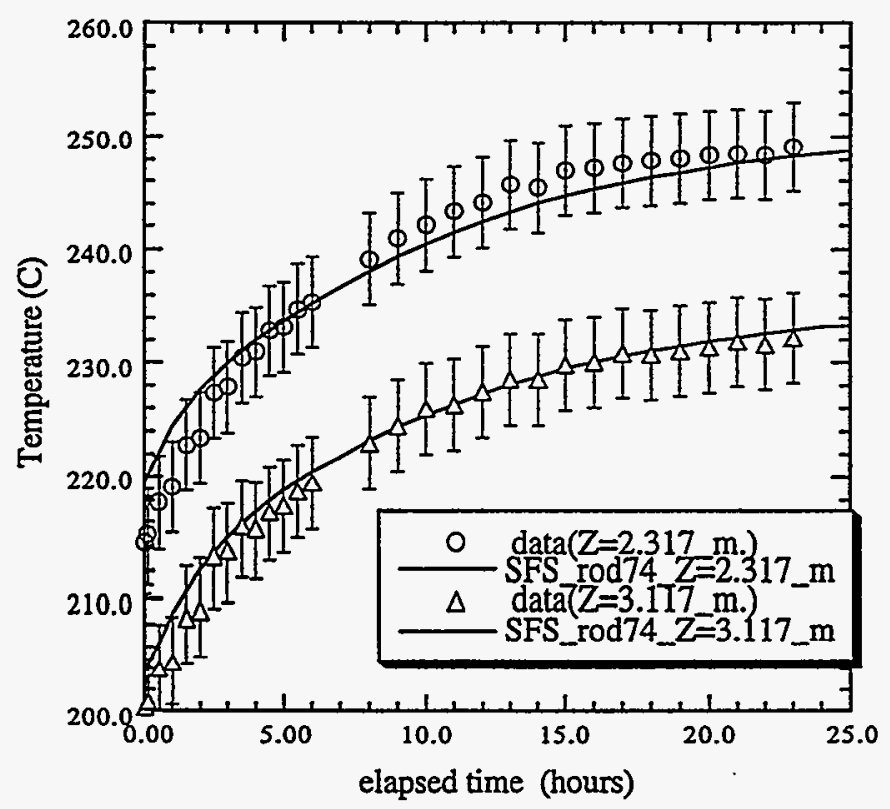

Figure 4.3. TN24P Transient: Backfill Changed from Helium to Air-Comparison of COBRA-SFS Calculations to Measurements from TC Lance D1-5 


\subsection{PSN/VSC-17 Cask Transient}

The PSN spent fuel storage cask was constructed by Pacific Sierra Nuclear Associates ${ }^{(a)}$ for longterm storage of consolidated spent fuel from pressurized water reactors. Performance testing was conducted for the U. S. Department of Energy and PSN by the Pacific Northwest Laboratory and the Idaho National Engineering Laboratory. The Electric Power Research Institute also participated in the program, as part of a cooperative program involving EPRI, DOE, PSN, and Wisconsin Electric Power Company, to evaluate horizontal modular storage systems for spent fuel. Testing was conducted at INEL's Test Area North (TAN) cask testing facility. The pretest preparations, performance testing, and post-test activities are fully documented elsewhere (McKinnon et al. 1992).

The PSN/VSC-17 spent fuel storage system is a passive container for storing up to 17 assemblies or canisters of irradiated nuclear fuel. The system consists of a Ventilated Concrete Cask (VCC), and a Multi-Assembly Sealed Basket (MSB). Diagrams of the cask structure are shown in Figure 4.4, with vertical and horizontal cross-sections. The concrete shell is a one-piece cylinder 20 in. $(50 \mathrm{~cm})$ thick with a steel inner liner. The shell provides structural support, radiation shielding, and an annular path for natural convection cooling of the basket assembly. The concrete bottom of the cask is an integral part of the cask shell, as shown. in Figure 4.4. It consists of a concrete slab 22 in. $(56 \mathrm{~cm})$ thick, with a steel plate on the inner surface that forms the bottom of the internal cavity. The cask lid consists of a steel weather cover capping the concrete annulus. The steel plate is bolted to the top of thesteel liner over a sheet rubber seal. The lower side of the cask lid is formed by the lid of the basket assembly, which consists of two steel plates with neutron shielding material sandwiched between them.

The basket assembly is of pressure vessel grade steel, and consists of an outer shell, the shield lid, and the fuel guide sleeve assembly, as shown in Figure 4.4. There is sufficient clearance between the outer shell of the basket and the storage sleeve assembly to ensure that differential thermal expansion during operation will not result in load transfer between the two structures. Interior structural support for the basket is provided by three steel shells wrapped around the framework of the fuel guide sleeves at the top, bottom, and middle of the assembly. These basket support structures are welded to the outer edges of the framework of the fuel guide sleeves and to the inner surface of the basket outer shell.

The basket lid is sealed with two o-rings, one of steel and one of elastomer, to provide a gas-tight seal to hold a backfill of helium, nitrogen, or vacuum. The depth of the cask cavity is sufficient to accommodate BWR fuel, and therefore an MSB support assembly is required when the cask is loaded with PWR fuel. This support assembly allows free circulation of air from the vented annulus along the underside of the basket assembly within the cask cavity.

(a) Pacific Sierra Nuclear Associates became Sierra Nuclear Corporation; in some of the documentation of the cask design and testing, SNC is used interchangeably with PSN in reference to the cask manufacturer. 
Decay heat generated in the spent fuel is transmitted through the basket wall to the air in the annulus between the basket and the concrete shell. Natural circulation can bring air in through the bottom vents and exhaust it to the environment through the top vents. The inlet and outlet vents are steel-lined penetrations arranged in a cruciform pattern, with the flow path constrained by a stepped structure to minimize radiation streaming, as illustrated in the cross-sectional diagram in Figure 4.4. The cask was loaded with Westinghouse $15 \times 15$ PWR spent fuel from the Surry 2 and Turkey Point plants. The fuel had been removed from the normal $15 \times 15$ rod array and consolidated, with the rods from two fuel assemblies in each canister. The canisters were of stainless steel, and consisted of a base and top locking cover. Each canister was loaded with 408 fuel rods, stacked on a triangular pitch. The top and bottom plates of the canister did not provide a gas-tight seal, but nevertheless severely limited the gas flow rate into or out of the canister.

Decay heat rates for the fuel were calculated from measured properties of the fuel using the ORIGEN2 computer code (Croff 1980). Decay heat from the individual canisters ranged from 700 to 1050 watts, with an average of about $877 \mathrm{~W}$ per canister. The canister placement was selected to produce 1/8th symmetry in heat generation within the basket, and to produce the maximum fuel temperature in the center of the MSB. The ORIGEN2 code was also used to predict the axial decay heat profiles, which are required for the COBRA-SFS model.

Performance testing of the PSN cask consisted of six test runs with three internal environments and four cask venting configurations, ranging from vents fully open to vents closed. In all tests, the cask was oriented vertically. Table 4.2 below summarizes the test conditions.

Steady-state COBRA-SFS calculations were performed for all six tests, both pre- and post-test, and are fully documented elsewhere (McKinnon et al. 1992). For the transient validation, however, it was difficult to determine an appropriate test for comparison to COBRA-SFS calculations. The beginning and end points of the transients were in most cases difficult to define, because of test procedures that effected changes in boundary conditions without allowing the system to reach a steady state for the previous set of changes. The conditions defined as "steady state" for Runs 1,2,3 and 6 in the steadystate validation only approximate steady state before the test procedures induce the next transient. The only conditions that were allowed to reach an unambiguous steady state were Run 5 (air backfill, vents open) and the transition from all vents closed to all vents open with helium backfill.

For Run 5, the test data show that the conditions in the cask at the point when the helium backfill is replaced by nitrogen are clearly not at steady state. This makes the resulting transient unsuitable as a transient validation case for COBRA-SFS, since it is not possible to determine the initial conditions accurately enough. It would, of course, be possible to begin the transient at the last approximately steady-state condition, which in this case would be the conditions for Run 3. This would require a transient calculation spanning something like 220 hours ( 9 days), which is not an impossible feat, but is rather long, even for COBRA-SFS. Closer inspection of the "steady-state" conditions for Run 3 shows that the steady state is not all that steady, however, and it would probably be necessary to go back to the "steady state" of Run 2, which would require a transient calculation spanning nearly 400 hours (16 days). 
Table 4.2. PSN/VSC-17 Cask Test Matrix

\begin{tabular}{|c|c|c|c|c|c|}
\hline $\begin{array}{l}\text { Steady } \\
\text { State Run } \\
\text { Number }\end{array}$ & $\begin{array}{l}\text { Approximate } \\
\text { Start Time of } \\
\text { Transient }\end{array}$ & $\begin{array}{l}\text { Approximate } \\
\text { Time New } \\
\text { Steady State } \\
\text { Obtained }\end{array}$ & $\begin{array}{l}\text { Approximate } \\
\text { Duration of } \\
\text { Transient }\end{array}$ & $\begin{array}{l}\text { Net Change in } \\
\text { Estimated Peak } \\
\text { Clad Temperature }\end{array}$ & Description of Transient \\
\hline $\mathrm{NA}$ & $\begin{array}{l}\text { initial cask } \\
\text { loading }\end{array}$ & \multicolumn{2}{|c|}{$\begin{array}{l}\text { Conditions do not reach steady } \\
\text { state before new changes } \\
\text { initiated on } 10 / 09 / 90\end{array}$} & & $\begin{array}{l}\text { Program start-up; all } \\
\text { vents open, vacuum, dry }\end{array}$ \\
\hline 1 & $10 / 09 / 90$ & $10 / 12 / 90$ & 96 hours & $40^{\circ} \mathrm{C}$ & $\begin{array}{l}\text { Replace air (vacuum) } \\
\text { backfill with helium; all } \\
\text { vents open }\end{array}$ \\
\hline 2 & $10 / 17 / 90$ & \multicolumn{2}{|c|}{$\begin{array}{l}\text { Very slow mild transient; end } \\
\text { point (on } 10 / 23 / 90 \text { ) treated as } \\
\text { steady state condition }\end{array}$} & $13^{\circ} \mathrm{C}$ & $\begin{array}{l}\text { Maintain helium backfill; } \\
2 \text { inlet vents blocked }\end{array}$ \\
\hline 3 & $10 / 24 / 90$ & $10 / 30 / 90$ & 144 hours & $44^{\circ} \mathrm{C}$ & $\begin{array}{l}\text { Maintain helium backfill; } \\
\text { all inlet vents blocked }\end{array}$ \\
\hline $\mathrm{NA}$ & $10 / 30 / 90$ & \multicolumn{2}{|c|}{$\begin{array}{l}\text { Conditions do not quite reach } \\
\text { steady state before new change } \\
\text { initiated on } 11 / 05 / 90\end{array}$} & & $\begin{array}{l}\text { Maintain helium backfill; } \\
\text { all vents open }\end{array}$ \\
\hline 5 & $11 / 05 / 90$ & $11 / 07 / 90$ & 24 hours & $30^{\circ} \mathrm{C}$ & $\begin{array}{l}\text { Replace helium backfill } \\
\text { with air; all vents remain } \\
\text { open }\end{array}$ \\
\hline 6 & $11 / 13 / 90$ & $11 / 15 / 90$ & 48 hours & $21^{\circ} \mathrm{C}$ & $\begin{array}{l}\text { Evacuate air to vacuum; } \\
\text { all vents remain open }\end{array}$ \\
\hline NA & $11 / 15 / 90$ & \multicolumn{3}{|c|}{$\begin{array}{l}\text { Initial rapid temperature decrease, followed by slow } \\
\text { gradual increase; conditions do not reach steady state } \\
\text { before new changes initiated on } 11 / 27 / 90\end{array}$} & $\begin{array}{l}\text { Replace air (vacuum) } \\
\text { backfill with helium; all } \\
\text { inlet vents blocked }\end{array}$ \\
\hline 4 & $11 / 27 / 90$ & \multicolumn{3}{|c|}{$\begin{array}{l}\text { Very slow mild transient, temperatures gradually } \\
\text { increasing; conditions at end point (on } 11 / 29 / 90 \text { ) } \\
\text { essentially steady state }\end{array}$} & $\begin{array}{l}\text { Maintain helium backfill; } \\
\text { all vents blocked }\end{array}$ \\
\hline NA & $11 / 29 / 90$ & $12 / 04 / 90$ & 96 hours & $53^{\circ} \mathrm{C}$ & $\begin{array}{l}\text { Maintain helium backfill; } \\
\text { all vents open }\end{array}$ \\
\hline
\end{tabular}

The final transient of the test series, in which the change from all vents closed to all vents open was the only change in the test conditions, was initiated from a relatively steady "steady state" (Run 4), and reached nearly steady state conditions after only about 96 hours. The change in peak measured temperature for this transient was approximately $53^{\circ} \mathrm{C}$, which was the largest change in this parameter observed in all the tests with this cask. In addition, this transient offered an excellent opportunity to test the effect of the unique feature of this cask design; the outer annulus that allows natural convection air . cooling of the MSB within the concrete shell of the cask. For these reasons, the final transient was selected as the case to evaluate for the transient validation calculations with COBRA-SFS for the PSN cask. 
The calculated results for this transient are compared to the test data in Figure 4.5. As can be seen from the plot, the COBRA-SFS results are in excellent agreement with the measured temperatures. The code results appear to be heading for a slightly more conservative steady state than the test data, but the difference is less than $7^{\circ} \mathrm{C}$. Given the overall measurement uncertainty and the unavoidable modeling uncertainties, particularly the geometric approximations required to represent the inlet and outlet vents for the annulus, and the difficulty in determining the appropriate surface heat transfer coefficient for the natural circulation flow in the annulus, these results constitute a very reasonable representation of the transient heat transfer in the cask. This comparison provides further evidence that COBRA-SFS correctly accounts for the transient terms in the solution of the energy equation, for both the solid material nodes and the fluid nodes. 


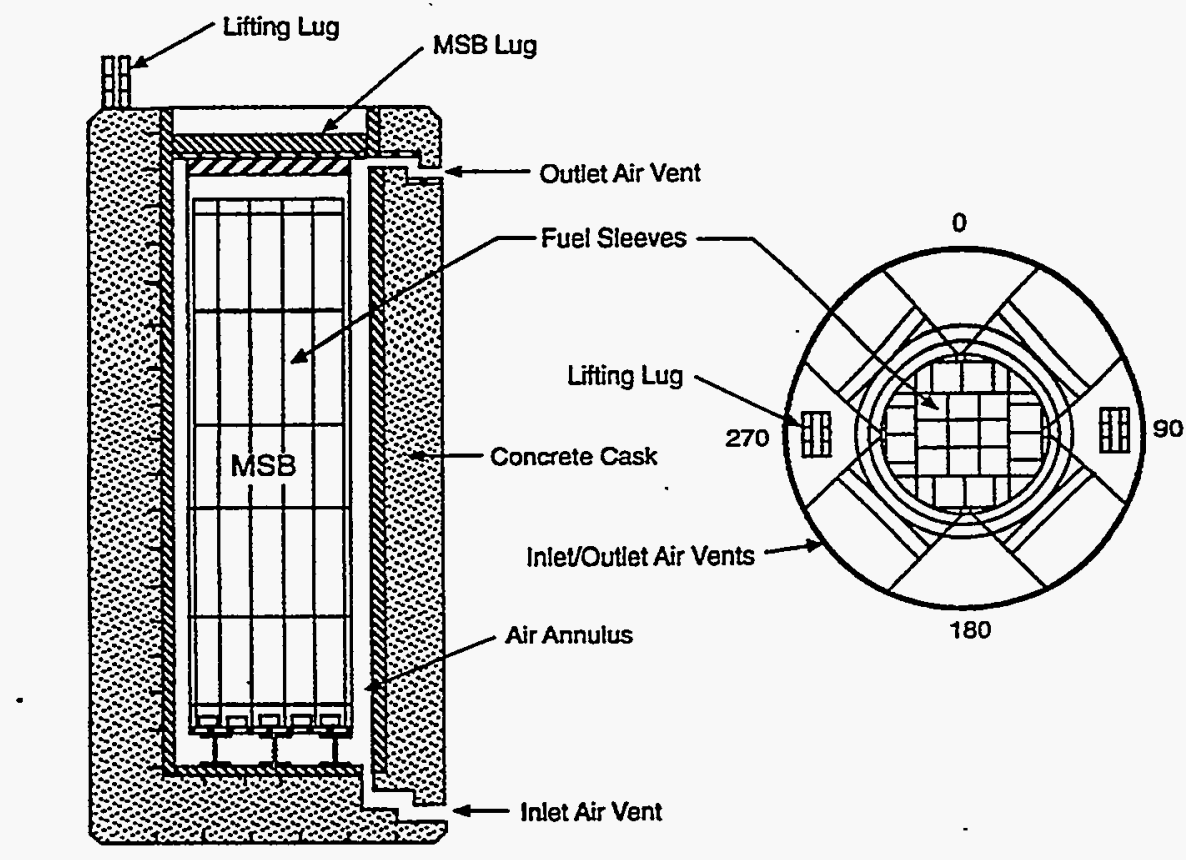

Figure 4.4. Diagram of PSN/VSC-17 Cask Structure

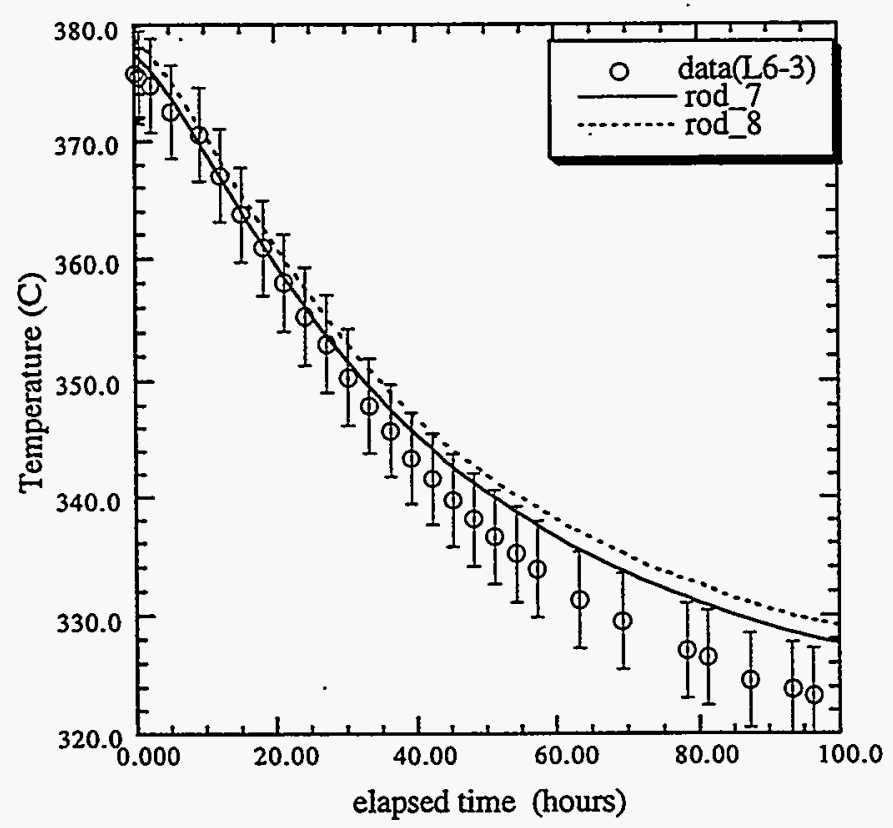

Figure 4.5. PSN/VSC-17 Transient: All Vents Closed Changed to All Vents Open, with Helium Backfill--Comparison of COBRA-SFS Calculations with Measurements from TC Lance L6, Thermocouple \#3 


\subsection{Conclusions and Recommendations}

The results presented in Section 3.0 showing comparisons of COBRA-SFS calculations to analytical solutions for flow and heat transfer conditions verify that the conservation equations for mass, momentum, and energy are properly implemented in the code. This does not, of course, mean that the code is entirely free of errors, but it does show that the results can probably be trusted, so long as they seem reasonable for a given problem. The results presented in Section 4.0 showing comparisons of COBRASFS calculations to transient tests in storage casks loaded with spent fuel validate the applicability of the code to the heat transfer and flow conditions encountered in such systems. The conservation equations in the code contain the appropriate physical models and constitutive relations to allow reasonably accurate calculations of the flow and heat transfer behavior in rod arrays, assemblies, and storage casks with complex designs.

Within the range of applicability of the models used in the code, the accuracy of a given COBRASFS calculation depends primarily on the accuracy of the representation of the system as it is presented to the code by means of the input. As with all computer codes, COBRA-SFS operates on the gigo law (garbage in, garbage out). The user must take care to represent the geometry with sufficient detail to capture the important material structures and flow paths within the system, select constitutive models (for wall friction, form drag, and heat transfer) that correctly represent the flow and heat transfer conditions in the cask, and specify material properties accurately for the fluid and solid structures that constitute the cask. This last item is particularly important in transient calculations, since the specific heat of many commercial materials (such as sealants, concrete, and metal alloys) is not always well characterized as a function of temperature, and in many cases will not be constant with temperature. Inaccuracies in these quantities will translate into inaccuracies in the energy storage terms for the energy equations, and will affect the ability of the code to follow the overall behavior of the transient.

The verification and validation calculations presented in this report show that COBRA-SFS is fully applicable to transient analysis of spent fuel assemblies and storage casks. However, specific applications of the code should still be evaluated against experimental data where possible, and sensitivity studies should be performed to determine that the model constructed represents the system accurately enough to produce reliable estimates of peak temperatures and other relevant performance measures. 


\subsection{References}

Arpaci, V. S. 1966. Conduction Heat Transfer, Addison-Wesley Publishing Company, Reading, Massachusetts.

Croff, A. G. 1980. ORIGEN-2 -- A Revised and Updated Version of the Oak Ridge Isotope Generation and Depletion Code, ORNL-5621, Oak Ridge National Laboratory, Oak Ridge, Tennessee.

Creer, J. M., T. E. Michener, M. A. McKinnon, J. E. Tanner, E. R. Gilbert, and R. L. Goodman. 1987. The TN-24P PWR Spent-Fuel Storage Cask: Testing and Analysis, EPRI-NP-5128, Electric Power Research Institute, Palo Alto, California.

Cuta, J. M., D. R. Rector, and J. M. Creer. 1984. Thermal-Hydraulic Analysis of Consolidated Spent PWR Fuel Rods, EPRI-NP-3764, Electric Power Research Institute, Palo Alto, California.

Cuta, J. M. and J. M. Creer. 1986. Comparisons of COBRA-SFS Calculations to Data from Electrically Heated Test Sections Simulating Unconsolidated and Consolidated BWR Spent Fuel, EPRI-NP-4593, Electric Power Research Institute, Palo Alto, California.

George, T. L., K. L. Basehore, C. L. Wheeler, W. A. Prather, and R. E. Masterson. 1980. COBRA-WC: $A$ version of COBRA for Single-phase Multi-assembly Thermal-Hydraulic Transient Analysis, PNL-2359, Pacific Northwest Laboratory, Richland, Washington.

Khan, E. U., W. A. Prather, T. L. George, and J. M. Bates. 1981. A Validation Study of the COBRA-WC Computer Program for LMFBR Thermal-Hydraulic Analysis, PNL 4128, Pacific Northwest Laboratory, Richland, Washington.

Lombardo, N. J., T. E. Michener, C. L. Wheeler, and D. R. Rector. 1986a. COBRA-SFS Predictions of Single Assembly Spent Fuel Heat Transfer Data, PNL-5781, Pacific Northwest Laboratory, Richland, Washington.

Lombardo, N. J., J. M. Cuta, T. E. Michener, D. R. Rector, and C. L. Wheeler. 1986b. COBRA-SFS: $A$ Thermal-Hydraulic Analysis Computer Code; Volume III: Validation Assessments, PNL-6049, Vol. 3, Pacific Northwest Laboratory, Richland, Washington.

McKinnon, M. A., T. E. Michener, M. F. Jensen, and G. R. Rodman. 1989. Testing and Analysis of the TN-24P PWR Spent Fuel Dry Storage Cask Loaded with Consolidated Fuel, EPRI-NP-6191/ PNL-6631/UC-85, Electric Power Research Institute, Palo Alto, California.

McKinnon, M. A. and R. E. Dodge. 1992. Performance Testing and Analysis of the VSC-17 Ventilated Concrete Cask, EPRI-TR-100305, Electric Power Research Institute, Palo Alto, California. 
Michener, T. E., D. R. Rector, J. M. Cuta, R. E. Dodge, and C. W. Enderlin. 1995. COBRA-SFS: $A$ Thermal-Hydraulic Analysis Code for Spent Fuel Storage and Transportation Casks, Documentation for Cycle 2, PNL-10782/UC-800, Pacific Northwest Laboratory, Richland, Washington.

Moore, F. K. 1964. Theory of Laminar Flows, Princeton University Press, Princeton, New Jersey.

Rector, D. R., C. L. Wheeler, and N. J. Lombardo. 1986a. COBRA-SFS: A Thermal-Hydraulic Analysis Computer Code, Volume 1: Mathematical Models and Solution Method, PNL-6049, Vol. 1, Pacific Northwest Laboratory, Richland, Washington.

Rector, D. R., R. A. McCann, U. P. Jenquin, C. M. Heeb, J. M. Creer, and C. L. Wheeler. 1986 b. CASTOR-1C Spent Fuel Storage Cask Decay Heat, Heat Transfer, and Shielding Analysis, PNL-5974, Pacific Northwest Laboratory, Richland, Washington.

Rector, D. R., J. M. Cuta, and N. J. Lombardo. 1986c. COBRA-SFS Thermal-Hydraulic Analysis of the CASTOR-1C and REA 2023 BWR Storage Casks Containing Consolidated Spent Fuel, PNL-5802, Pacific Northwest Laboratory, Richland, Washington.

Rector, D. R., and T. E. Michener. 1989. COBRA-SFS Modifications and Cask Model Optimization, PNL-6706, Pacific Northwest Laboratory, Richland, Washington.

Rowe, D. S. 1973. COBRA-IIIC: A Digital Computer Program for Steady-State and Transient ThermalHydraulic Analysis of Rod Bundle Nuclear Fuel Elements, BNWL-1695, Pacific Northwest Laboratory, Richland, Washington.

Slattery, J. C. 1972. Momentum, Energy, and Mass Transfer in Continua, McGraw-Hill Book Co., New York.

Stewart, C. W., C. L. Wheeler, R. J. Cena, C. A. McMonagle, J. M. Cuta, and D. S. Trent. 1977. COBRA-IV: The Model and the Method, BNWL-2214, Pacific Northwest Laboratory, Richland, Washington.

Szymanski, P. 1932. Some Exact Solutions of the Equations of Motion for Flow in a Cylinder Tube, J. Math Pures Appl., Ser. 9, 11:67.

Wheeler, C. L., R. A. McCann, N. J. Lombardo, D. R. Rector, and T. E. Michener. 1986. HYDRA and COBRA-SFS Temperature Calculations for CASTOR-1C, REA-2023, CASTOR-V/21, and TN-24P Casks, Proceedings, Third International Spent Fuel Storage Technology Symposium and Workshop, Vol. 1, S77-S98, CONF-960417, National Technical Information Service, Springfield, Virginia.

Wiles, L. E., N. J. Lombardo, C. M. Heeb, U. P. Jenquin, T. E. Michener, C. L. Wheeler, J. M. Creer, and R. A. McCann. 1986. BWR Spent Fuel Storage Cask Performance, Test, Volume II: Pre- and Post-Test Decay Heat, Heat Transfer, and Shielding Analysis, PNL-5777, Vol. 2, Pacific Northwest Laboratory, Richland, Washington. 


\section{Distribution}

No. of

Copies

OFFSITE

11 DOE/Office of Scientific and Technical Information

A. Brownstein

U.S. Department of Energy

1000 Independence Avenue

Washington, DC 20585

W. J. Danker

Office of Civilian Radioactive Waste Management

RW-33

U.S. Department of Energy

Washington, DC 20585

3 Electric Power Research Institute

P.O. Box 10412

Palo Alto, CA 94303

ATTN: R. W. Lambert

R. L. Yang

A. Machiels

Fluor Engineers

Advanced Technology Division

333 Michelson Drive

Irvine, CA 92730

Office of Civilian Radioactive Waste Management

RW-421

U.S. Department of Energy

Washington, DC 20585

ATTN: L. Stewart

J. R. Williams
No. of

Copies

J. V. Massey

Sierra Nuclear Corporation

5619 Scotts Valley Drive, \#240

Scotts Valley, CA 95066

D. H. Nyman

Westinghouse Hanford Company

P.O. Box 1970, B5-24

Richland, WA 99352

J. Richardson

WESTON Technical Support Team

955 L'Enfant Plaza SW

Washington, DC 20024

T. L. Sanders

Sandia National Laboratory

P.O. Box 5800

Albuquerque, NM 87185

M. L. Smith

Virginia Power Company

5000 Dominion Blvd.

Glen Allen, VA 23060

Technical Library

Battelle Memorial Institute

Office of Nuclear Waste Isolation

505 King Avenue

Columbus, $\mathrm{OH} 43201$

2 U.S. Nuclear Regulatory Commission

Office of Nuclear Materials Safety and Safeguards

Mail Stop 6-H-3

Washington, DC 20555

ATTN: F.C. Sturz

M. B. Raddatz

Distr.1 
PNNL-11883

No. of

Copies

ONSITE

DOE Richland Operations Office

D. E. Trader K8-50

22 Pacific Northwest National Laboratory

Z. I. Antoniak

J. M. Creer

J. M. Cuta

C. W. Enderlin

T. E. Michener (14)

M. A. McKinnon

K. P. Recknagle

D. R. Rector (2)
K7-15

K7-80

K7-15

K7-15

K7-15

K8-34

K7-15

$\mathrm{K} 7-15$ 